\title{
ON THE GEIGER-NUTTALL RELATIONSHIP*
}

\author{
BY SUKUMAR BISWAS
}

\begin{abstract}
(Reccived for publication, Nov, 27, 1948)
ABBTRAOT. It is shown in the present rork that the Geiger-Nuttall relationship is more satisfactory and refined when the $\log \lambda, E$ curve is plotted for isotopes having the same atomic number $Z$. From the theoretical stndy or $\alpha$-emission it has been shown that only points, referring to nuclei having the same atomic number, fall on a continuous curve. Iven in this case there appears to be some deviation of the actual curve from the theoretical one on both ends (for nuclei having shortest and longest lives). The experimental data of all $a$-active nuclei have heen systematically studied and the modified Geiger-Nuttall curves have been drawn for all elements from $B i$ to $P^{\prime} u$. The $\alpha$ and $\beta$ stability considerations are used to predirt the probable $\alpha$ or $\beta$ activities as yet unk nown. Some of the nuclei suspected of weak a-activily are $\mathrm{UX}_{\mathrm{l}^{234}} \mathrm{M}^{3} \mathrm{shh}^{228}$ and $U \mathrm{Y}^{231}$.
\end{abstract}

\section{INTRODUCTION}

The Geiger-Nuttall relation, $\log \lambda=a+b E$, which was first obtained from empirical clata has played a very fundamental part in the understanding of nuclear phenomena. It was the basis of Gamow's famous work on the escape of $\alpha \cdot$ j)article through polential barriers.

The latest position of this famous relation is given in Gamow's "Structure of Atomic Nuclei," p. 86. As given there, the $(\log \lambda, E)$ curve for three radioactive serjes is not a continuous one but it is shown to consist of three distinct ones corresponding to the $\mathrm{U}, \mathrm{AcU}$ and $\mathrm{Th}$ series. Even the curve for a single series, e.g., for Ac is not contintous. When these curves were compiled the half-lives and energies of some of the products particularly the extremely short-lived and extremely long-lived ones were not very accurately known. But recently much more data on these points liave been obtained and the series have been prolonged and it appears advisable to reexamine the whole question. The present work has been undertaken with the point in view.

Recently Berthellot (1942) suggested that the points on the Geiger-Nuttall diagram $(\log \lambda, E$ curve) fall on a continuous line if the data belong to yuclei having the same charge number $Z$. This has been verified by Broda and Feather (1947) in case of Po and led to the interesting discovery that $\operatorname{Ra}$, well-known for its $\beta$-activity is also slightly $\alpha$-active, The ratio of $\alpha$-activity to $\beta$-activity is found as $\sim 10^{-7}$ to I.

* Comtinunicated by Prof. M. N. Saba. 


\section{THEOR H'TICAL BACEGROUND}

The object of the present work is to examine critically whether the Geiger-Nutall curve, $\log \lambda$ against $K$, is a smooth one only when $\alpha$-active isotopes of the same atomic number are plotted. Let us now interpret the above assumption of constancy of atomic number. $\%$, in Geiger-Nuttall law from theoretical point of view.

The phenomenon of spontancous $\alpha$-radioactivity was first explained by Gannow (1929) and Condon and Gurney (r929) who calculated the trans. mission factor of the potential barrier by the application of wave-mechanical method. Since then a large number of investigators have attacked this problem assuming different types of potential ficld in the nucleus. These results differ in the method of attack and the degree of accuracy of the results, but the main term in the transmission factor is the same as given by Gamow.

The disintegration constant $\lambda$ is calculated from the transparency of the potential barrier either by the semi-classical argument by Laue (1929) or by the assumption of complex eigen-values as is done by (amow (1937). The form of the potential barrier is assumed to be an inverse square field $\mathbf{u}_{1}$, to a distance $r_{0}$ and a rectangular hole of potential $U$ for distance less than $r_{0}$. The transparency factor, calculated by Saha (r944) and Iaue's semi-classical arguments yicld the relation :

$$
\lambda=\frac{v}{r_{0}} c^{-2 k}
$$

where

$$
\begin{aligned}
v & =\text { velocity of the a-particle } \\
r_{0} & =\text { radius of the nucleus } Z-2 . \\
2 K & =\frac{16 \pi e^{2}(Z-2)}{h v}\left(u_{0}-\sin u_{0}^{-} \cos u_{0}\right) \\
u_{0} & =\cos ^{-1}\left[\frac{m v^{2} r_{0}}{4 e^{2}(Z-2)}\right]^{\frac{1}{2}}
\end{aligned}
$$

Using the complex eigen function method, the following relations are obtained betwecn $\lambda$ and $E$, for $l=0$ (Preston, J947)

$$
\begin{aligned}
& \mu=-\tan u_{0} \tan \left(\mu k r_{0}\right) \\
& \lambda=\frac{2 v}{r_{0}} \frac{\mu^{2} \tan \frac{u_{0}}{\mu^{2}+\tan ^{2} u_{0}} c^{-2 k}}{}
\end{aligned}
$$

where

$$
\mu=\left(I-U / E_{a}\right)^{\frac{1}{2}}, k=\frac{2 \pi m \psi}{h} \text {. }
$$

It can be easily seen that if we have $U=0, \mu=\mathrm{I}$, the equation $(.3)$ reduces to

$$
\lambda=\frac{v}{r_{0}} \sin 2 u_{0} \cdot c^{-2}
$$




\section{Geiger-Nuttall Relationship}

'This expression has been used by Sexl (1933). 'Thus three expressions. for $\lambda$ are available.

$$
\begin{aligned}
& \lambda=\frac{v}{r_{0}} e^{-2 k} \\
& \lambda=\frac{v^{\prime}}{r_{0}} \sin 2 u_{0} \cdot e^{-2 k} \\
& \lambda=\frac{2 v}{r_{0}} \cdot \frac{\mu^{2} \tan u_{0}}{\mu^{2}+\tan ^{2} u_{0}} e^{-2 k}
\end{aligned}
$$

The factors $\sin 2 u_{0}, \frac{2 \mu^{2} \tan u_{0}}{\mu^{2}+\tan ^{2} u_{0}}$ are of the order of nuity. The value of $\lambda$ changes so rapidly with small adjustments in the value of the constant $r_{0}$ in $e^{-2 k}$ that the multiplying factor is not of much consequence.

In these calculations the effect of relative motion of the $7-2$ nucleus is to be taken into account. So we are to use total energy $E=E_{\mathrm{a}}\left(\mathrm{I}+\frac{m_{a}}{m_{r}}\right)$, relative velocity of $\alpha$-particle $v=v_{\alpha}\left(\mathrm{I}+\frac{m_{a}}{m_{r}}\right)$ and reduced mass $m=\frac{m m_{r}}{m_{a}+m_{r}}$ in place of $l_{a}, v_{\alpha}$ and $m_{\alpha}$ respectively.

Using the first formula, $(\mathrm{r})$,

$$
\log _{10} \lambda=\log _{10} v-\log _{10} r_{0}-4343 \gamma\left[u_{0}-\sin u_{0} \cos u_{0}\right] \quad \ldots \quad \text { (5) }
$$

where

$$
\begin{aligned}
& \gamma=\frac{16 \pi c^{2}(Z-2)}{h v}, \\
& \log \gamma=9^{\circ} 2476+\log (Z-2)-\log v \\
& u_{0}=\cos ^{-1}\left\{\frac{m v^{2} / 2}{2 e^{2}(Z-2) / r_{0}}\right\}^{\frac{1}{2}}
\end{aligned}
$$

$$
2 \log \cos u_{0}=6.8549-.4343 \frac{m a_{1}}{m_{r}}+\log r_{0}+2 \log v-\log (Z-2)
$$

From relation (5), we sce that $\log \lambda$ depends not only on the velocity of the ejected $\alpha$-particle but also on the atomic number $(Z-2)$ and the nuclear radius $r_{0}$. So in general case it can not be represented in a two dimensional graph. The curve, $\log \lambda$ against $E$, is approximately valid if $(Z-2)$ is kept constant since the variation of $r_{0}$ is small from one isotope to other ones. The nuclear radius $r_{0}$ may be assumed to vary as the cube root of mass number of the nucleus.

The reason why Geiger-Nuttall could get a more or less smooth curve by plotting $\log \lambda$ against $E$, is, as pointed out by Cramow (1937, p. I04), due to the fact that variation of $Z, E$ and $r_{0}$ in a radioactive series is practically 
monotonic as we go down the series. Anomalies occur in the original GeigerNuttall curve where this tegularity breaks down. Thus the Geiger-Nuttall curves with constaut $\angle$, will be more refined and less susceptible to anomalies.

The validity of the theoretical relation could be examined if the theoretical curve of $\log \lambda$ against $E$ for constant $\%$, could be drawn and compared with the experinentally observed ones. But unfortunately this cannot be directly done since the above relation contains three variables $\lambda, l i$ and $r_{0}$, of which $\lambda$ and $E$ are known experimentally. The other terms, the nuclear radius $r_{0}$ cannot be determined as yet from any other independent observation. Hence what is done in this case for verifications is to see whether the values of $r_{0}$ calculated from the thcoretical relation with the help of experijientally observed values of $\lambda$ and $J$, are consistent for different nuclei. As it has been shown by different investigators, (Gamow 1937, Preston I946, I947) that the value of $r_{0}$ is more or less consistent excepting for the actinium series. For other nuclei $r_{0}$ nearly follows the relation $r_{0}=R 4^{\frac{1}{3}}$ obtained from liquid drop model. No satisfactory explanation is at present available for the abnormally low values of $r_{0}$ for $\mathrm{ThC} \rightarrow \mathrm{ThC}^{\prime \prime}, \mathrm{RaC} \rightarrow \mathrm{RaC}^{\prime \prime}$ and $\mathrm{AcC} \rightarrow \mathrm{AcC}^{\prime \prime}$.

As the experimental curves are plotted as $\log \lambda$ against $E$ (in $\mathrm{MeV}$ ) let us transform the erquation (5) in terms of energy in MeV. Tior numerical calculation we use the relation

$$
\begin{aligned}
& \log \lambda=21.8428+\frac{1}{2} \log E_{v}+.217 \frac{m_{a}}{m_{r}}-\log r_{0} \\
& -\mathrm{I} .104 \cdot \frac{Z-2}{E_{v} \frac{1}{2}\left(\mathrm{I}+\frac{m_{\alpha}}{m_{r}}\right)^{\frac{1}{2}}} \cos ^{-1}\left[.5896 \frac{E_{0} r_{0}^{\frac{1}{3}}}{(Z-2)^{\frac{1}{3}}}\right]+.6504 \frac{(Z-2)^{\frac{1}{2} r_{0} \frac{1}{2}}}{\left(I+\frac{m_{0}}{m_{r}}\right)^{\frac{1}{2}}}
\end{aligned}
$$

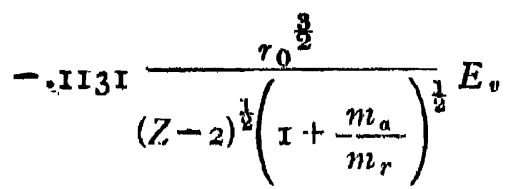

The relation (6) exhibits explicit dependence of $\log \lambda$ on the disintegration energy $E$, charge number $Z-2$ of the product nucleus and radius $r_{0}$. Since $r_{0}$ varies as $A^{\natural}$, the effect of variation of $r_{0}$ from one number to other will be small; but if $Z$ varies for different members, the variation will be much pronounced. So constancy of $Z$ becomes a necessary condition for a two dimentional curve.

The Geiger-Nuttall law has been stated as

$$
\log \lambda=a+b E
$$




\section{Geiger-Nuttall Relationship.}

But the actual theoretical relation is much complicated as seen from the relation (6). As it will be seen in later section that Po contains largest number of $\alpha$-active isotopes, the theoretical relations deduced abbve can be conveniently compared with experimentally observed values. Taking an average value of $r_{0}=8.63 \times 10^{-13} \mathrm{~cm}$. (for $\mathrm{Po}^{216}$, $\mathrm{Th}_{\mathrm{A}}$ ), the following theoretical relation for $P o$ is obtained from the relation (6).

$$
\begin{aligned}
& \log \lambda=a-\frac{b}{E_{v}} \cos ^{-1}\left(c E_{v}^{2}\right)+d \log E_{v}-e E_{v} \\
= & \left.380664-8971-\cos ^{-1} \quad .1923 E_{v}{ }^{2}\right)+\frac{1}{2} \log E_{v}-.3225 E
\end{aligned}
$$

With relation (8) the theoretical curve given in $\mathrm{Fig}$. ( $\mathrm{I} a$ ) is drawn. The curve passing through experimental points is given in Fig.r (c). The agreement with the experimental curve $(c)$ is seen to be satisfactory, in the middle part from (214) to (218) but on both sides the theoretical curve diverges from the experimental one. However instead of taking $r_{0}$ constant for all isotopes we can take the variation of $r_{0}$ from one isotope to other into account according to the relation, $r_{0}=R \cdot A^{\text {i }}$ 'Thus another thcoretical curve (b) (Fig. I)

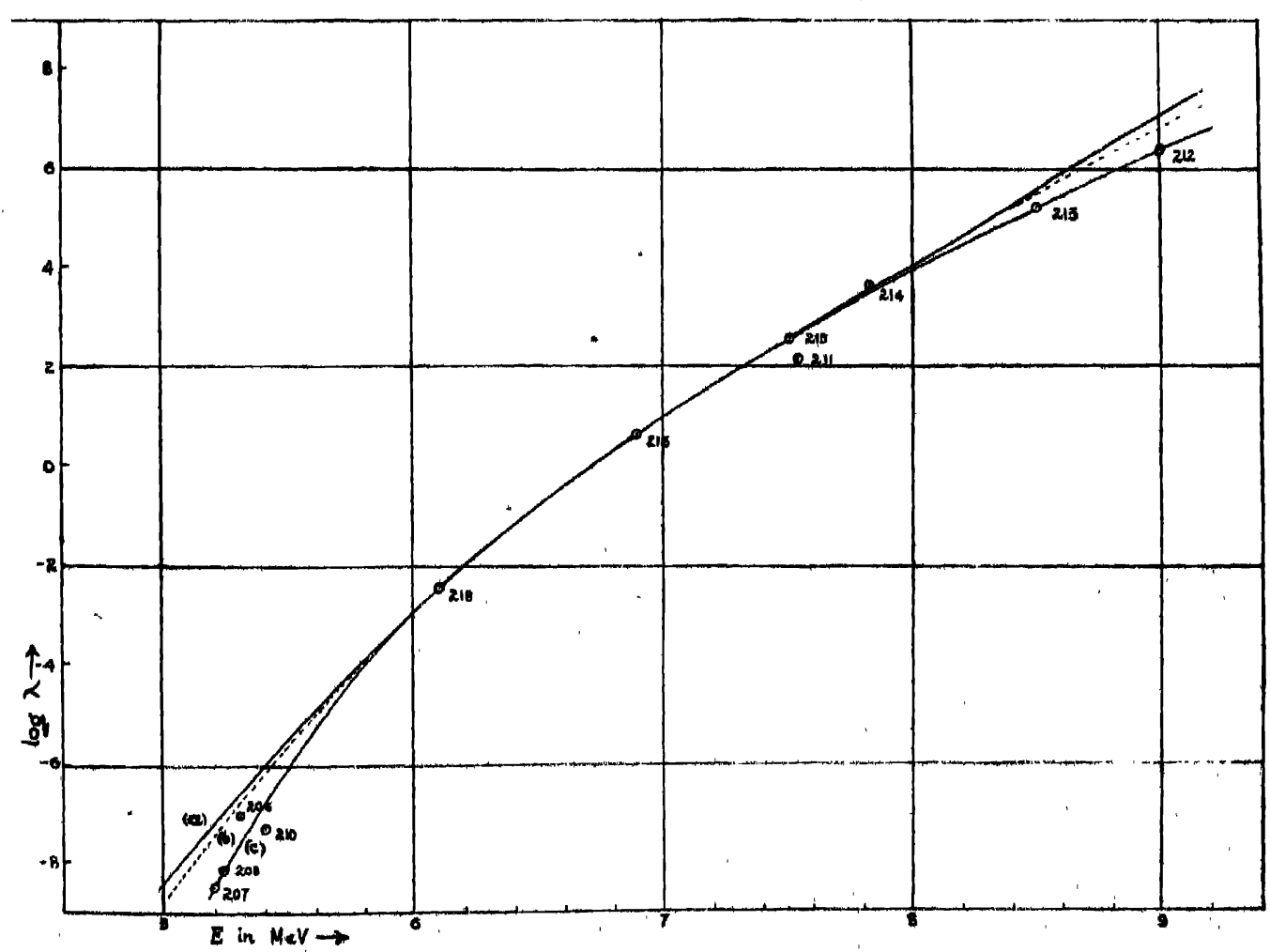

FIG. I

is drawn froin relation (6). The curve (b), alproaches the experimental curve $(c)$ at the end; but discrepancy still remaius at the two ends, which shows that the theory of $\alpha$-particle emission fails to account for very short lived products as well as very long-lived ones. 
IXPLANATIONOF TIE MTIHOD.

Now the modified Ceiger-Nuttall curves are to be drawn for each elcment starting from $\mathrm{Bi}$. For dealing with the large amount of datal we have made use of the nuclear chart originally given by Saha, Sirkar and. Mukherjee (r940). The usefulness of this chart has been extcnded by the work of Saha and Saha (rg46) and others on "Nuclear Iinergetics and $\beta$-activity". The part of the diagram dealing with our work is reproduced in Fig. 2.

As the chart shows all o-radio-activity appears to cease with $\mathrm{Pb}$ (82). This means, that the activity is too small to be measured. But from $8_{3}$ onwards, \%-activity has been found in many nuclei. Some of these nuclei are also simultaneotsly $\beta$-active and it is possible that, many of which have been found so long only $\%$ - or only $\beta$-active may be found, as has been found by Feather in the case of Rali, to show the other type of activity on a very much feebler scale. We have therefore made use of our criterion for $\beta$-activity as given by Biswas and Mukherjec (I948) for dealing with each individual cases.

The correct determination of the data namely $\lambda$ and $E$ is the most important task. For $E$ we have taken, not the energy with which the $\%$-particle comes out, but the total energy of the reaction. As is well-know1, this is given by the formula

$$
E=E_{0} \quad \begin{array}{cc}
A \\
A-4
\end{array}
$$

In the case of a nucleus which decays both ways by $\alpha$-disintegration, $\beta$-decay or $K$-capture, experinents give us only the composite life $T$. As is wellknown

$$
\stackrel{I}{T}=\frac{I}{T_{\alpha}}+\frac{I}{T_{\beta}} .
$$

When we are considering $\lambda, E$ relation for $\alpha$-rays, we require $T_{n}$. To obtain this we nust know the second relation, the ratio of $\frac{T_{a}}{T_{\beta}}=\frac{\lambda_{\beta}}{\bar{\lambda}_{\alpha}}$, which gives the ratio of the particles disintegrating by $\beta$-decay to that by a-decay. In many cases this ratjo is known but in many cases we reed. have recourse to surmise. These points will be discussed in the proper places.

\section{EXCITED ST $\Lambda$ TIS IN $\alpha$-IS MISSION:}

It is well-linown that many $x$-active nuclei do not emit a-particles of one energy, but a-particles of several energy groups are found. This is due to the formation of excited states of the initial or the product nuclets in $\alpha$-emisThe nuclei emitting complex $\%$-spectra can be divided into two classes. 
TABLE I

Bismuth $\left(8_{3}\right)$

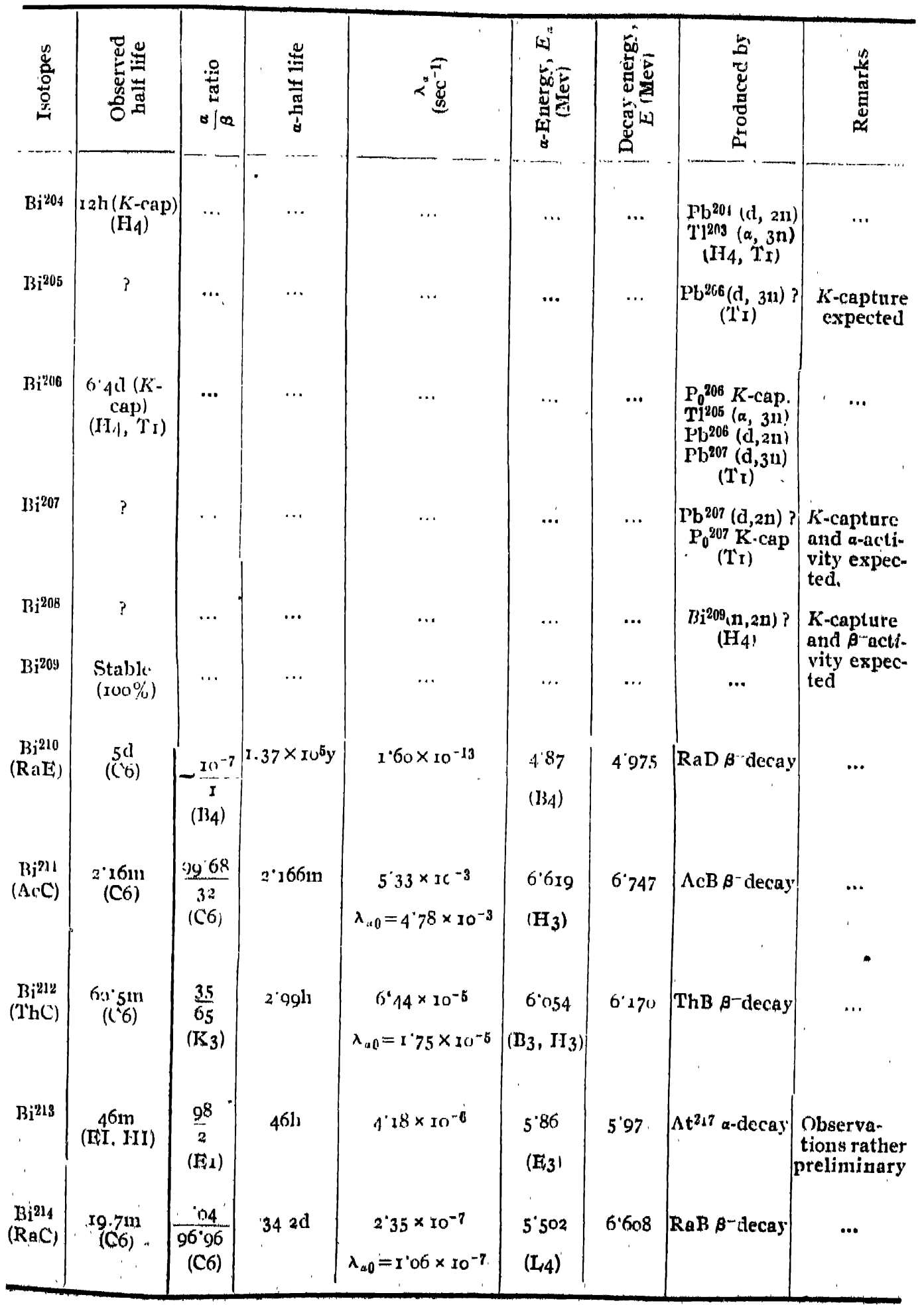


(x) Class I: In this class, the a-particles of maximum energy have highest intensity (group (J) and the intensity of other groups are smaller but of the same order as the group $O$. This is due to the formation of the excited states of the product nucleus. The exainlles are ' $\mathrm{ThC}^{\prime} \rightarrow \mathrm{ThC}^{\prime \prime}$, $\operatorname{RaAc} \rightarrow \mathrm{AcX}$, etc.

In the present discussion, the a-emission between the ground states of two nuclei (group $O$ ) are cousidered. Hence the observed disintegration constant $\lambda_{a}$ is to be corrected so as to give prartical disintegration constant for the zcro group $\lambda_{a n}$. Taking the case of $\mathrm{Th}^{\prime \prime \prime} \rightarrow \mathrm{Th}^{\prime \prime}$ we find that intensity of grouj, $O$ a-particles is $27.2 \%$ of the total intensity. So $\lambda_{a 0}$ will be $27.2 \%$ of the total $\lambda_{a}\left(6.44 \times 10^{-i}\right)$. Thus the corrected $\lambda_{a 0}$ is $1.75 \times$ 10. -5

Similar correction is applied for all a-emitters of Class I as will be referred to later on.

(2) Class II : 'This class includes a few a-active nuclei where the a-particles of lowest energy have the highest frequency and a-particles of higher energy are very infrequent, relative intensity being of the order of $I$ in $10^{6}$. This is due to the existence of excited states in the initial nucleus. Only the normal a-particles (group O) are included in this discussion. Since the intensities of other groups of a-particles are very small compared to group $O$, we can pul $\lambda_{a 0} \approx \lambda_{a}$ and no correction for the complex spectrum is required.

The examples of this type are $\mathrm{ThC}^{\prime} \rightarrow$ 'ThD, $\mathrm{RaC}^{\prime} \rightarrow \mathrm{RaD}$.

\section{$\left(8_{3}\right)$ Bismuth}

The isotopes of $\mathrm{Bi}$ range from mass number 204 to 214 , All the relevant data are given in Table I.

$\mathrm{Bi}^{204}$ : This recently obtained isotope of $\mathrm{Bi}$ shows a $\mathrm{I} 2 \mathrm{hr} K$-capturing activity. This is an agreement with the findings of Biswas and Mukherjee (1948) on $\beta$-energetics consideration.

$\mathrm{Bi}^{205}$ : No distinct activity assignable to $\mathrm{Bi}^{205}$ could be found in the reaction expected. It is expected, from the studies of Biswas and Mukherjee (I948) to be a $K$-capturing nucleus.

$\mathrm{Bi}^{206}$ : The $6.4 \mathrm{~d} K$-capturing activity of this nucleus is in agreement with: findings of Biswas and Mukherjee (1948).

$\mathrm{Bi}^{207}$ : No activity could be assigned to $\mathrm{Bi}^{207}$ which is expected in the reaction studied. According to Biswas and Mukberjee ( 1948 ) this ought to be a $K$-capturing nuclets with long life.

Corson et al (1940) reports the production of $85^{211}$ by the reaction $\mathrm{Bi}^{20}$ $\left(a, 2_{n}\right)$ and showed that it is dually active, $60 \%$ being a-active $40 \% \mathrm{~K}$-active. The product of the a.active branch would be $\mathrm{Bi}^{207}$, but he was unable to trace any aclivity of $\mathrm{Bi}^{207}$. 


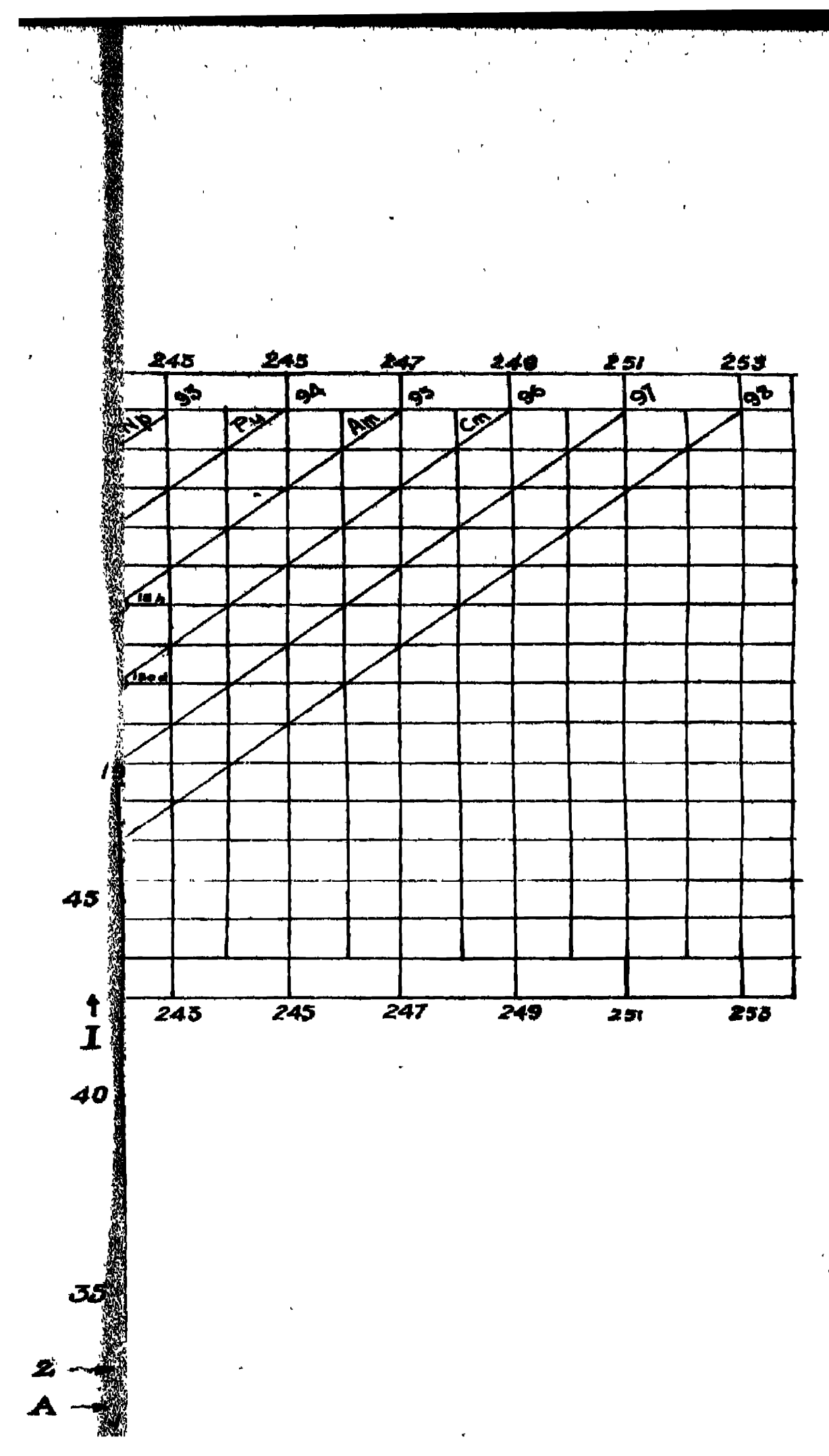

[Facing page $5^{6}$ 
$\mathrm{Bi}^{208}$ : The production and mode of decay of this isotope are as yet uncertain. According to Biswas and Mukherjee (1948) it ought to show both $K$-capture and $\beta^{-}$-activity.

$\mathrm{Bi}^{209}$ : This is the only stable isotope of $\mathrm{Bi}$.

$\mathrm{Bi}^{210}$ : ( $\left.\mathrm{RaE}\right)$ : Broda and Feather (r947) have recently shown that in addition to $5 \mathrm{~d} \beta$-activity, a small fraction of RaE decays by a-activity to $\mathrm{Th}^{200}$. The branching ratio of $a$ and $\beta$ is estimated as $\sim I \times 10^{-7}: \mathrm{I}$. The energy of a-particles has been obtained from the equivalence of energy-release in the two branches as shown in Fig. 3 . The value of $E_{a}$ is to be confirmed by direct experiment. A little alteration in the value of branching ratio and $l_{\alpha}$ will shift the point on the curve to a small extent.

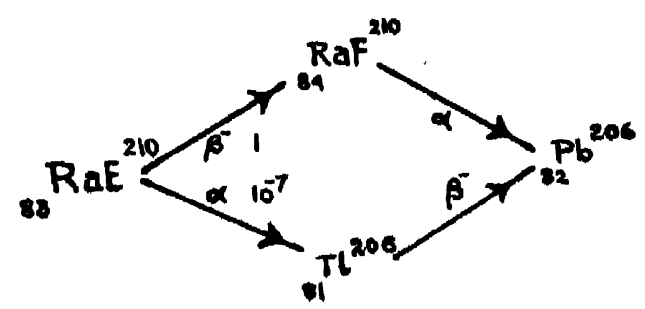

Fig. 3.
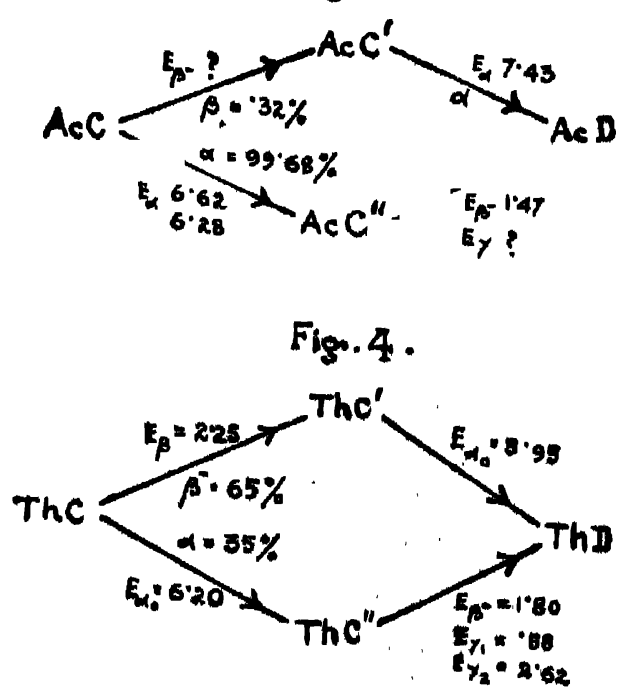

Fig. 5.

$\mathrm{Bi}^{211}$ : $(\mathrm{AcC})$ : The dual disintegration scheme of $\mathrm{ACC}$ is given in FiG. 4. The main disintegration of $\mathrm{ACC}$ is by a-emission (99.68\%) to $\mathrm{AcC}$. Two groups of a-particles are emitted. The complex a-spectra fall in Class I. The intensity "of group $O$ a-particles is $84 \%$. Thus $\lambda_{a}=5.33 \times 10^{-3} \mathrm{sec}^{-1}$ is corrected to give $\lambda_{a 0}$ which becomes $4.478 \times 10^{-3} \mathrm{sec}^{-1}$. This isotope falls close to the $\log \lambda_{a,}$ curve for $\mathrm{Bi}$. 
'The energy of the $\beta$-emission in $A C C \rightarrow A c C$ ' is not yet determined. Iirom the equivalence of evergy-release in two branches, $E \boldsymbol{\beta}^{-}$-comes out as $.66 \mathrm{MeV}$. 'l'he study of the disintegration of $\mathrm{AcC}$ is not yet complete.

$\mathrm{Bi}^{212}\left(\mathrm{~T}_{1} \mathrm{C}\right)$ : The dual disintegration scheme of $\mathrm{ThC}$ is well studied by Ellis and this is given in Fig. 5 . In the a-disintegration branch $\mathrm{ThC}^{\prime} \rightarrow \mathrm{ThC}$, the observed composite half-life is resolved to give a-half-life and $\lambda_{a}$. The a-spectra is complex consisting of five components (Class I). The intensity of Group $O$ a-particles in $27.2 \%$, and $\lambda_{a 0}$ is calculaled as $1.749 \times 10^{-5}$ from the value of $\lambda_{a}\left(6.4 .39 \times 10^{-5}\right)$. This isotope falls on the smooth $\log \lambda-E$ curve for $\mathrm{Bi}$.

$\mathrm{Bi}^{21: 3}$ : This isotope is the corresponding $\mathrm{C}$-product in the newly discovered $(4 \mathrm{n}+\mathrm{J})$ radio-active series. The data for branching ratio, composite half-life and a-cnergy releasc are taken after the determination of English et al (1947). The study of this new series is rather preliminary and further investigation is required. $\mathrm{Bi}^{214}(\mathrm{RaC})$ : The complete disiutegration sclieme of $\mathrm{RaC}$ to $\mathrm{RaD}$ has not yet been established. In the disintegration $\mathrm{RaC}$ to $\mathrm{RaC}^{\prime \prime}$ 1 wo groups of a-particles having energies of 5.612 and $5.549 \mathrm{MeV}$ have intensities of $45.4 \%$ and $54.6 \%$. The a-disintegration constant is calculated from composite halflife; this $\lambda_{a}$ is corrected to give partial disintegration constant $\lambda_{a 0}$ which becones $\mathrm{I} .056 \times 1 \mathrm{O}^{-7} \mathrm{sec}^{-1}$.

\section{The Refined Geiger-Nultali Curve For Bi}

With the data given in Table I, the (veiger Nuttall plot, $\log \lambda$ aganst $E$, is made for the isotopes of $\mathrm{Bi}$ (Fig. 6). The points lic close to a smooth curve excepting $\mathrm{Bi}^{214}(\mathrm{RaC})$. This curve is somewhat different than that given by Broda and Feather (I947) in the study of a-activity of RaIi. The curve given by them is drawn through the points corresponding to a-particles other than the zero group, whereas the present curve is drawn for Group $O$ a-particles of the isotopes of $\mathrm{Bi}$. The a-active isotopes of $\mathrm{Bi}$ includes $\mathrm{C}$ products and it has been shown by Gamow (1937) that nowe of these $\mathrm{C} \rightarrow \mathrm{C}^{\prime \prime}$ bodies show normal behaviour.

\section{(84) I'olonium}

Polouium contains largest number of a-active nuclei. Its 1sotopes range from mass number 206 to 218 with exception of 209 and 217 . The relevant data are given in Table II. .

Po200: This recently oblained Poloniun isotope exhibits simultaneous a-emission and $K$-capture $)$ rocesses. T'he $K$-capture activity of this even-even nucleus is duc to its position. in the extreme right flank of the I-group. As pointed out by Biswas and Mukherjee, this mucleus is a good confirmation of the Saha-Suha theory (1946).

No daughter of $\mathrm{Po}^{20}$ by o-emission has been reported. The product $\mathrm{Pb}^{202}$ should be a-active. 
TARLE II

Polonium ( 84 )

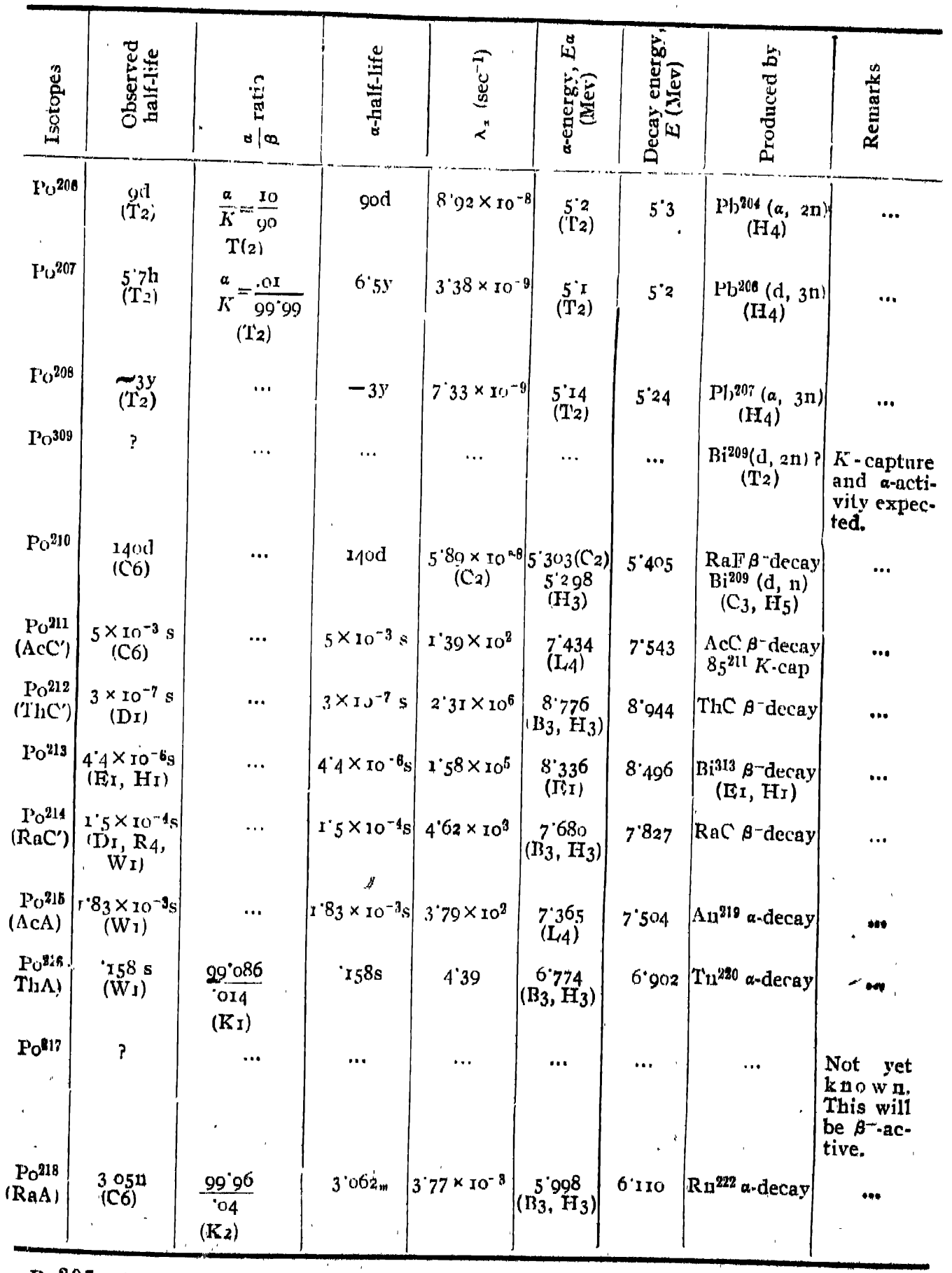

Po207: This also is a simultaneous $a$ and $K$-active nucleus. The high $K$ capture process $(99.99 \%)$ is in agreement with Biswas and Mukherjee's findings. No daughter of $\mathrm{Po}^{207}$ is found. $\mathrm{Po}^{207}$ will decay to $\mathrm{Bi}^{207}$ by $K$. capture. As given before $\mathrm{Bi}^{207}$ should decay by $K$-capture. 
$P^{20 k}$ : The 3 year $\alpha$-activity of $\mathrm{Po}^{008}$ is in agreement with the stability rule. According to Biswas and Mukherjee, this even even nucieus should lave no $\beta^{-}$or $K$-capture activity.

$\mathrm{Po}^{211 \theta}$ : No activity could the assigned to $\mathrm{Po}^{20 y}$ which is expected in the raction studied, $\mathrm{Bi}^{200}(\mathrm{~d}, 2 \mathrm{n}) \mathrm{Po}^{\prime \prime \prime}$. This isotope will dccay by, $K$-capture (Biswas and Muklierjee, 1948) as well as by $x_{\text {-activity. }}$

$\mathrm{Po}^{210}$ : The investigation of Chang (1946) revealed that $\mathrm{Po}^{210}$ (RaF) does not emil homogencous a-rays, but seven groups of particles are prescrit. The intensity ratios of the higher order groups to the main group are at variance with the present theory of a-enission of excited states. The to-energy of Group () is highest and the relative intensity is ro", compared to other groups whose cnergics are smaller than the main group. 'Thus the a-spectra do not fall in either of Class I or Class II as stated before. 'l'aking the experimental observation as correct, Po ${ }^{210}$ presents a problem, hitherto unknown and unexplained, in a-emission.

$\mathrm{Po}^{211}$ : $\left(\mathrm{AcC}^{\prime}\right)$ : 'The normal a-particles of $7.434 \mathrm{MeV}$ from $\mathrm{AcC}^{\prime}$ is surely attended by long range a-particles of very low intensity as in the case of ' $\mathrm{T}$ " $\mathrm{C} C$ ' and $\mathrm{RaC}^{\prime}$. 'These have not yet been studied. Accurate determination of the extrcmely short half-life of $\mathrm{AcC}^{\prime}$ is required as no recent data are available for this. The a-spectra of $\mathrm{AcC} \rightarrow \mathrm{AcD}$ should fall in Class II as in other $\mathrm{C}$-products, and hence no correction for $\lambda_{a}$ is required.

The absence of $\beta$-activity of this nucletus follows from the studies of Biswas and Mukherjee (I948).

$\mathrm{Po}^{212}\left(\mathrm{ThC}^{\prime}\right):$ The spectra of $\mathrm{ThC}^{\prime} \rightarrow \mathrm{ThD}^{2}$ has been completely investigated and with the main group of $8.776 \mathrm{MeV}$ two long range anparticles of very small intensity are present. The complex $\alpha$-spectra fall in Class II and no correction of $\lambda_{a}$ is required. The short half-life $\left(3 \times 10^{-7} \mathrm{sec}\right)$ has been accurately determined by Dunworth (5939).

No $\beta$-activity is possible for this even-even nucleus.

$\mathrm{Po}^{213}$ : In the same line with 'ThC' and $\mathrm{AcC}^{\prime}$, this isotope is the corresponding $\mathrm{C}^{\prime}$ hody of the newly discovered $(4 n+1)$ radio-active series. 'The half-life is reported as $4.4 \times 10^{-6} \mathrm{sec}$. Further investigation is sure to show long range $\alpha_{-1}$ articlus of very swall relative intensity.

No $\beta$-activity of this nucleus is possible as shown by Biswas and Mukherjee.

$\mathrm{Io}^{214}\left(\mathrm{RG}_{\mathrm{G}} \mathrm{C}^{\prime}\right)$ : It has been observed by Lewis \& Bowden that twelve long range a-groups of very snall relative intensity are present with the main group of a-particles. The number of $\gamma$-rays, due to transitions 


\section{Geiger-Nuttall Relationship}

between these levels, as pointed out by Ellis, should be many more than at present observed. The half-life has been accurately determined by Dunworth (r939), Rotblat (I94I) and Ward (r.942).

This $\alpha$-spectra of Class II require no correction for $\lambda_{\alpha}$. The $\beta$-stability of this nucleus is accounted for by its even-even property.

$\mathrm{Po}^{215}$ (AcA): The anspectrum is siniple as observed by Lewis and Bowden (1934). The short half-life, I. $8_{3} \times 10^{-1}$ sec, has been accurately measured by Ward (1942). According to Biswas and Mukherjee loc. cit., low energy $\beta$-emission is probable for $\mathrm{Po}^{215}$ (AcA). The isotopes, ThA and $\operatorname{RaA}$ of two other radioactive series have bcen observed to cmit low intensity $\beta$-rays in addition to strong a-activity (Karlik and Bernert, 1943), Thus the predicted $\beta$-activity of very weak inteusity will be in agreement with the A-products of two other series. This will be worthy of further investigation.

$\mathrm{Po}^{216}$ (ThA): Karlik and Bernert (r943a) showed that low intensity $\beta$-ray branching (.014\%) exists for this strong a-active nucleus. The $\beta$-ray energy has nol yet been measured. Very low energy $\beta$-emission from this cven-even nucleus is explained by its position in the flank of the group $I=48$. This is in confirnation of Saha-Saha thcory (1946).

T'he short hall-11fe $(.158 \mathrm{sec})$ has been accurately measured by Ward (1942).

Po"17 : This isotope of Po is yet nnknown. T'his should belong to $(411+x)$ radioactive scries; but $85^{217}$ is the only known isotope of this mass number in $(4 n+1)$ radioactive series. If ever obtained, this will be $\beta^{-}$active of very short half-life.

$\mathrm{Po}^{21 k}(\mathrm{RaA}):$ 'The investigations of Karlik and Bernert (r943b) revealed a low intensity $\beta$-ray branching $(.04 \%)$ tor this predominantly a-active nucleus. The $\beta$-ray energy has not yet been measured. The $\beta$-activity of this even-even nucleus is due to its position in the extreme flank of Group $I=50$, and is in good agreement with Saha-Saha theory (1946). As indicated by Biswas and Mukherjee, $\beta$-ray energy-release is expected to be $\sim .2 \mathrm{MeV}$.

\section{The Geiger-Nuttall Curve for Po.}

Since Po contains largest number of a-active isotopes, the validity of the refined Geiger-Nuttall relationship can be tested with the data provided by it. The curve, $\log \lambda$ against $E,(F i g .6)$ is plotted with the data given in. Table II. It is observed that almost all the isotopes fall on a smooth curve. Small deviations occur for $\mathrm{Po}^{11 !}\left(\mathrm{AcC}^{\prime}\right), \mathrm{Po}^{210}$ and $\mathrm{Po}^{200}$. In case of $\mathrm{Po}^{2 \times 1}\left(\mathrm{ACC}^{\prime}\right)$ it has alteady been pointed out 


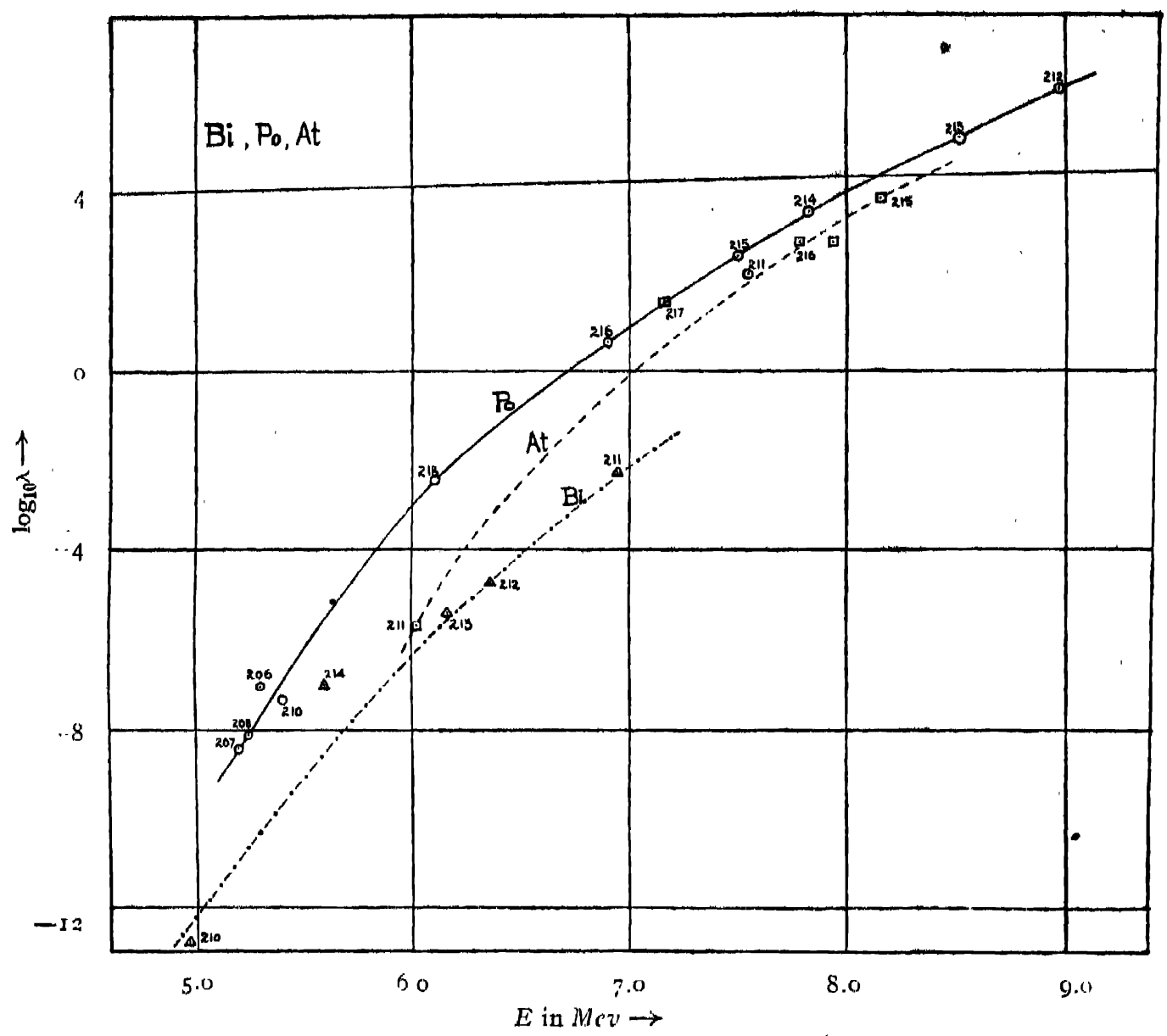

FIG. 6

that the short half-life $\left(5 \times \mathrm{IO}^{-1} \mathrm{sec}\right)$ has not been measured witl 1 accuracy in recent ycars. Po ${ }^{210}$ exhibits a new type of a-activity as indicated before. The data for the oller isotope, $\mathrm{Po}^{206}$ are rather preliminary. Thus the proposed refinement of the Geiger-Nuttall relation is seen to hold good.

\section{(85) Astatine}

At present five isotopes of element 85 are known, all of which show u-activity. The data for one isotope is insufficient. The relevant data are given in Table III.

$85 \mathrm{At}^{211}$ : This jsotope was obtained in artificial transmutation by 40 $\mathrm{MeV} \alpha$-particies on $\mathrm{Bi}^{200}$ by Corson et al (1940). The observed $K$-capture activity of this, in addition to $\alpha$-activity is well explained by the $\beta$.energetics for $I=4 I$ (Biswas and Mukherjec, I948).

$A t^{21 K}$ : This isotope is $\alpha$-active and $\beta$-stable. The $\beta$-stability of this is in agreenlent with $\beta$-energetics considerations. 
TABI.E III

Astatine (85)

\begin{tabular}{|c|c|c|c|c|c|c|c|c|}
\hline $\begin{array}{l}\text { 总 } \\
\text { 总 }\end{array}$ & 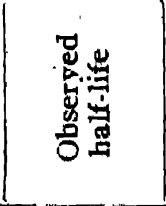 & $\underbrace{0}_{0}$ & 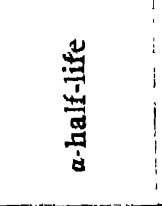 & $2 \bar{x}$ & 总 & 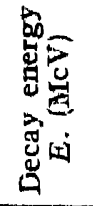 & 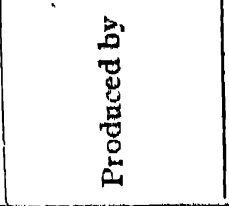 & $\begin{array}{l}\text { 常 } \\
\text { 品 } \\
\text { 量 }\end{array}$ \\
\hline At ${ }^{211 !}$ & $\begin{array}{l}7.511 \\
\text { (c) } 51\end{array}$ & 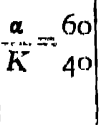 & 12. $5 \mathrm{~h}$ & $1.54 \times 10^{5}$ & $\begin{array}{l}5.94 \\
\text { (c5) }\end{array}$ & 6.03 & $\begin{array}{c}\mathrm{Ri}^{200}(\alpha, 2 \mathrm{n}) \\
(\mathrm{C}-5)\end{array}$ & $\begin{array}{l}\alpha \text {-decay pro } \\
\text { duct not yet } \\
\text { observed. }\end{array}$ \\
\hline$A t^{215}$ & $\left(\begin{array}{l}10^{-1 / s} \\
\hdashline 2 a)\end{array}\right.$ & & $\sim^{10}-0^{-43}$ & $6.93 \times 10^{3}$ & $\begin{array}{l}8.00 \\
\left(G_{2} \alpha\right)\end{array}$ & 8.15 & $\mathrm{Ir}+219 \alpha$-decay & \\
\hline$A t^{216}$ & $\begin{array}{l}\sim_{\left(r^{-3}\right.}^{-3} \mathrm{~s} \\
\left(i_{2} a\right)\end{array}$ & & $\sim \mathrm{ro}^{-3_{\mathrm{S}}}$ & $6.93 \times 10^{2}$ & $\begin{array}{l}7 . \mathrm{G}_{4}\left(\mathrm{G}_{2} a\right) \\
7.79(\mathrm{KI})\end{array}$ & $\begin{array}{l}7.79 \\
7.93\end{array}$ & $\left|\begin{array}{cc}\operatorname{Ir}^{220} & a \text {-decay } \\
\mathrm{ThA}^{216} & \boldsymbol{a} \text {-decay }\end{array}\right|$ & $\begin{array}{l}\text { Also } \beta^{-a c-} \\
\text { tivity ex- } \\
\text { pected }\end{array}$ \\
\hline$A t^{217}$ & $\begin{array}{l}2 . \mathrm{I} \times \mathrm{IO}^{-2} \mathrm{~s} \\
(\mathrm{EI}, \mathrm{H} \mathrm{H})\end{array}$ & & $2.1 \times 10^{-2} \mathrm{~s}$ & 33.0 & 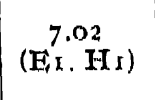 & 7.16 & $\mathrm{Fr}_{2}^{\mathrm{g} 221} \alpha$-decay & \\
\hline$A t^{218}$ & $\underset{\left(\mathrm{K}_{2}\right)}{\mathrm{Iew} \text { Sec? }}$ & & & & $\begin{array}{l}6.63 \\
(\mathrm{~K} ; 2)\end{array}$ & 6.75 & $\operatorname{RaA} 218$-decay & $\begin{array}{l}\text { Data in- } \\
\text { complete. }\end{array}$ \\
\hline
\end{tabular}

85 $\mathrm{At}^{210}$ : This isotope is formed in weak $\beta^{-}$-branching of ThA (Karlik and Bernert, I943a) and by a-decay of $\mathrm{Fr}^{220}$. The half-life is stated as $\sim 10^{-3} \mathrm{~s}$. The a-cnergy is given as $7.64 \mathrm{MeV}$ according to earlier determination and 7.97 MeV according to Jater determination. This is also expected to show $\beta^{-}$-activity, but probably this is ovcrshadowed by the more intense a-activity.

$85 \mathrm{At}^{17}$ : This isotope is a member of the ncwly discovered $(4 \mathrm{n}+\mathrm{r})$ radio-active series. Its a-activity has been observed; but it may be also $\beta^{-}$-active with sulall energy-release.

$85 \mathrm{At}^{219}$ : This isotope is produced in the $\beta$-btanching of $\mathrm{RaA}$ which is only $0.04 \%$. The value of half-life is uncertain and is given as several seconds. The a-encrgy is reported as $6.63 \mathrm{MeV}$ by Karlik and Bernert (1943). Further investigation of this isotope is required. Taking the value of $E_{a}$ as correct, the half-life of $A t^{21 "}$ may be estimated from the Geiger-Nuttall curve for At. This comes out as $\sim{ }_{5}$ sec.

\section{The Geiger-Nuttall Curve for At,}

Of five a-active isotopes of At, the available data permit to plot four of them. As seen in Fig. 6 these lie on smooth $\log \lambda, E$ curve within the limits of experimental error. This curve is similar to that of Po and lies below the latter. This Geiger-Nittall curve for At is useful to determine half-life from a knowledge of $E_{a}$ and vice versa for any other isotope with incomplete data. Using this curve half-life of At ${ }^{218}$ comes out as $-{ }^{-} 5 \mathrm{sec}$. 
(86) Radon

All three nown isotopes of $\mathrm{Rn}$ are $\alpha$-active. The relevant data are given in Table IV.

$\mathrm{Rn}^{21 R}$ : This isotope is obtained in the co-lateral chain of Ra-series. The a-energy is not directly obtained from $\mathrm{Rn}^{21 \mathrm{~d}}$ but is assigned to it in order of half-life.

$\mathrm{Rn}^{210}(\mathrm{An})$ : The a-spectra of $\mathrm{Rn}^{219}$ is complex consisting of $4 \mathrm{groups}$. The intensity of the zero group a-particles is $70 \%$. Accordingly the value of $\lambda a_{10}$ is . $124 \mathrm{sec}^{-1}$.

TABLE IV

Radon (86)

\begin{tabular}{|c|c|c|c|c|c|c|c|c|}
\hline $\begin{array}{l}\text { 惫 } \\
\text { 总 } \\
\text { 总 }\end{array}$ & 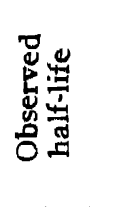 & 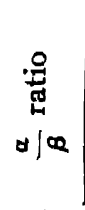 & 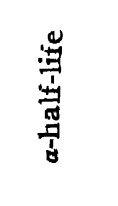 & 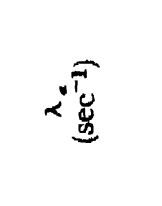 & 影 & 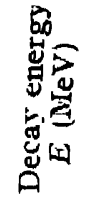 & 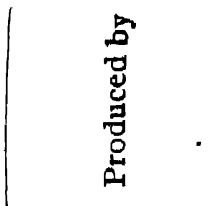 & 粱 \\
\hline $\mathbf{R n}^{218}$ & $\begin{array}{l}.019 \mathrm{~s} \\
(\mathrm{~s} 12)\end{array}$ & & . & 36.5 & $\begin{array}{c}7.1 \\
\text { (Siz) }\end{array}$ & 7.83 & $\mathrm{Ra}^{272} a$-decay & • \\
\hline $\begin{array}{c}\mathrm{Rn}^{219} \\
\left(\Lambda_{11}\right)\end{array}$ & $\begin{array}{l}3.92 \mathrm{~s} \\
(\mathrm{c} 6)\end{array}$ & & $3.92 \mathrm{~s}$ & $\lambda_{a 0}^{.17}=.12$ & $\begin{array}{l}6.82 \\
\left(\mathrm{H}_{3}\right)\end{array}$ & 6.95 & $A \subset X^{223 \alpha}$-decay & \\
\hline $\begin{array}{c}\mathrm{K}_{11^{230}} \\
\left(\mathrm{~T}_{12}\right)\end{array}$ & $\underset{(c 6)}{54.5 \mathrm{~s}}$ & & $54.5 \mathrm{~s}$ & $1.27 \times 10^{-2}$ & $\begin{array}{c}6.28 \\
\left(\mathrm{~B}_{3}, \mathrm{H}_{3}\right)\end{array}$ & 6.40 & 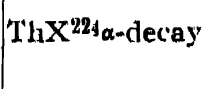 & \\
\hline $\mathrm{Rn}^{221}$ & $?$ & & & & & & & $\begin{array}{l}\beta^{-} \text {-activity } \\
\text { e xpected. }\end{array}$ \\
\hline $\mathrm{Rn}^{222}$ & $\begin{array}{c}3.825 \mathrm{~d} \\
(\mathrm{c} 6)^{2}\end{array}$ & & $3.825 \mathrm{~d}$ & $2.10 \times 10^{-6}$ & $\begin{array}{l}5.486 \\
\left(\mathrm{~B}_{3}, \mathrm{H}_{3}\right)\end{array}$ & $5.5^{87}$ & $\mathrm{Ra}^{222 \sigma_{\alpha} \text {-decay }}$ & \\
\hline
\end{tabular}

$\mathrm{Rn}^{220}(\mathrm{Tn})$ : The a-particles from $\mathrm{Tn}^{220}$ are homogeneous as observed by Briggs (1936) and Lewis and Bowden (1934).

$\mathrm{Rn}^{221}$ : This isotope of $\mathrm{Rn}$ is not yet known. This may be formed if a small a-branching exists in $\mathrm{Ra}^{225}$ which is not unlikely. $\mathrm{Rn}^{221}$ will be predominantly $\beta^{-}$-active.

$\mathrm{Rn}^{222}$ : The a-particles of $\mathrm{Rn}^{222}$ are homogeneous according to the observation of Lewis and Bowdun (1934) and Briggs (1936).

The $\beta$-stability of all three known isotopes of Rn follows from the studies of Biswas and Mukherjee (1948).

\section{Geiger-Nuttal: Curve for Rn.}

$\because$ With the data given a Table IV, the $\log \lambda, E$ curve is drawn from the isotopes of Rn (Fig. 7). It is seen that the three points lie on a smooth curve 
while the one of $\mathrm{Rn}^{210}$ falls outside, A redetermination of $\lambda$ and $R_{a}$ of $\mathrm{Rn}^{21}$ is required.

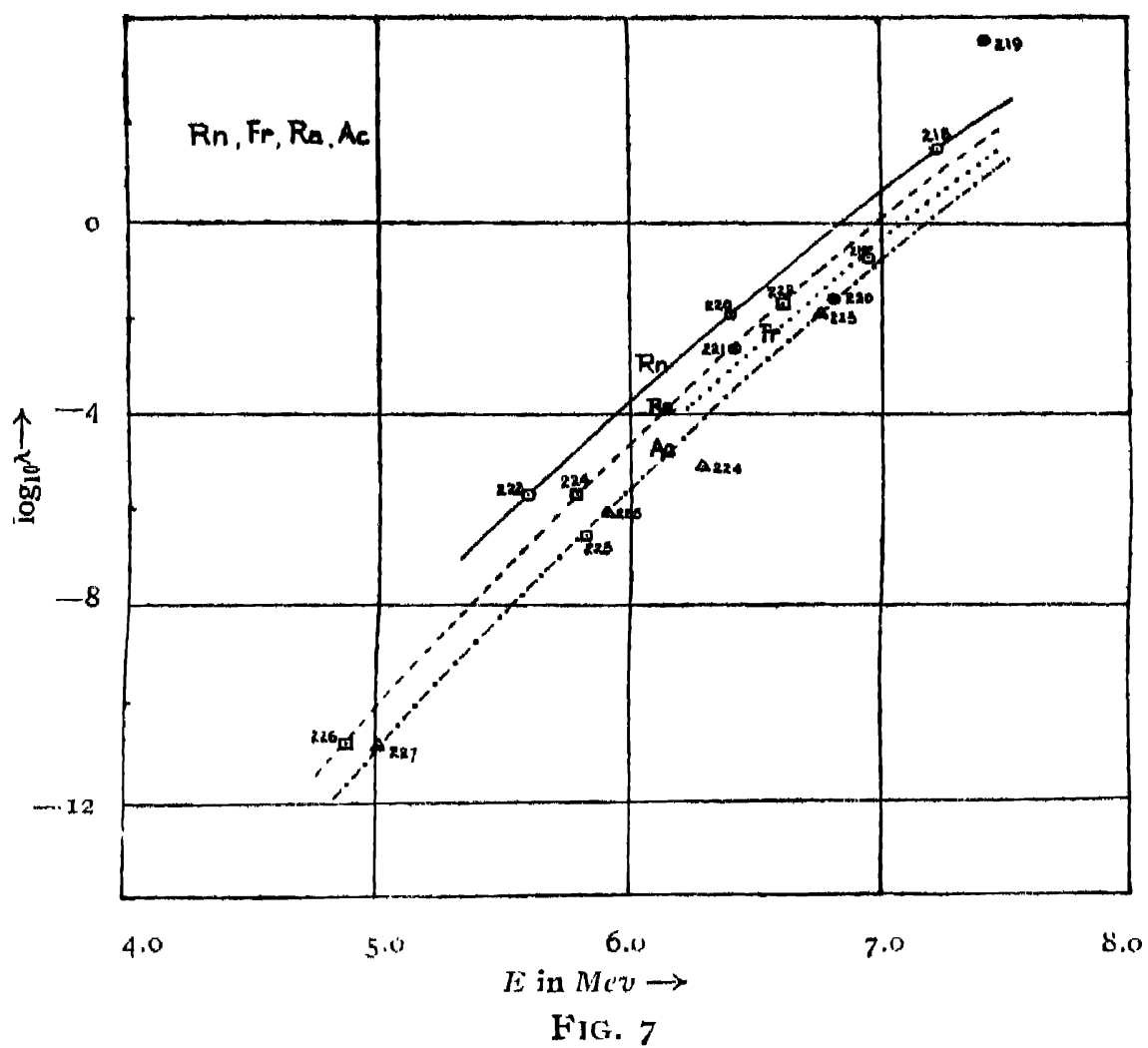

(87) Franciun

At present four isotopes of element 87 are known of which one is $\beta^{-}$-active. The relevant data are given in Table $\mathrm{V}$.

$\mathrm{Fr}^{231 "}$ : 'This is obtained in a colateral chain of Ac series recently synthe. sised. As expected this is $\beta$-stable.

$\mathrm{Fr}^{220}$ : This isotope is observed as $x$-active. This is expected to be also $\beta^{- \text {-active. }}$

$\mathrm{Fr}^{221}$ : This isotope is a member of the recently discovered $(4 \mathrm{n}+\mathrm{r})$ radioactive series. 'The $\beta$-encrgetics curves for $I=47$ shows that this will be $\beta$-stable.

$\mathrm{Fr}^{22:}$ : This isotope is not yet known. This isotope will be $\beta^{-}$-active.

$\mathrm{Fr}^{223}$ : (AcK) Perey and Lecoin (r939) discovered a small a-activity of $A c^{227}, \alpha: \beta$ branching ratio being $\mathrm{I}: 99$. The a-decay product is $87 \mathrm{Fr}^{22.8}$ which is ealled AcK. This decays by $\beta^{-}$-activity to $\mathrm{AcX}^{22.3}$.

The $\beta^{-}$-activity of $\mathrm{Fr}^{23}$ is in agreement with the studies of Biswas and Mukherjee (I948). The $\beta^{-}$-ray energy of $1.2 \mathrm{MeV}$ is stipported by theoretical considerations, but no $\gamma$-ray of so high energy, $>_{3} \mathrm{MeV}$, as reported by them, should exist with this isotope. 
'T'ABI,E V

Francium (87)

\begin{tabular}{|c|c|c|c|c|c|c|c|c|}
\hline 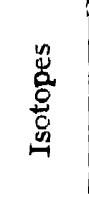 & 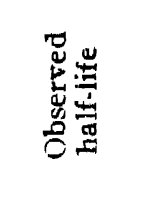 & 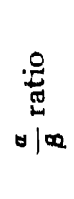 & 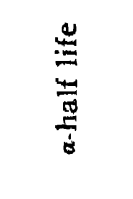 & $x^{T}$ & 递 & 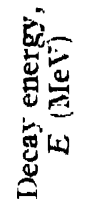 & 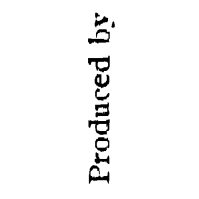 & 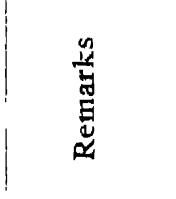 \\
\hline $\int^{1} \mathrm{r}^{219}$ & $\begin{array}{c}\left.-I_{1}\right)^{-4} \mathrm{~s} \\
\left(\mathrm{G}_{2} a\right)\end{array}$ & & $-10^{-4} s$ & $6.9 \times 10^{3}$ & $\begin{array}{l}730 \\
(\mathrm{G}: 2 a)\end{array}$ & 7.43 & $\Lambda c^{223} a$-der ay & $\begin{array}{l}\text { Precise } \\
\text { value of } \\
\lambda \text { is re- } \\
\text { quired. }\end{array}$ \\
\hline $\mathrm{Fr}^{220}$ & $\sim_{(\mathrm{G} 2 \alpha)}^{30 \mathrm{~s}}$ & & $\sim_{30 \mathrm{~A}}$ & $2.3 \times 10^{-2}$ & $\begin{array}{l}6.63 \\
(G \times 2 a)\end{array}$ & $6.8 \mathrm{I}$ & $\Lambda c^{224} \alpha$-decay & $\begin{array}{c}\beta^{-} \text {-activity } \\
\text { also ex- } \\
\text { pected. }\end{array}$ \\
\hline $\mathrm{F}_{\mathrm{r}}{ }^{221}$ & $\left(\begin{array}{c}5 \mathrm{~m} \\
\left.\mathrm{~m}, \mathrm{H}_{1}\right)\end{array}\right.$ & & $5 \mathrm{~m}$ & $2.3 \times 10^{-3}$ & $\begin{array}{l}6.31 \\
\left(\mathbf{E}_{I}\right)\end{array}$ & 6.42 & $\mathrm{Ac}^{225} a$-decay & \\
\hline I'r ${ }^{222}$ & 8 & & & & & & & $\begin{array}{l}\text { Tlisis will be } \\
\boldsymbol{\beta}^{-} \text {-active. }\end{array}$ \\
\hline $\begin{array}{l}\operatorname{li}_{\mathrm{r}} \mathrm{r}^{223} \\
(\Lambda \mathrm{CK})\end{array}$ & 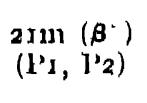 & & & & & & $\mathrm{Ac}^{227} \alpha$-deiay & \\
\hline
\end{tabular}

Geiger-Nullall curvc for Fr.

As the experimental data are approximate, the point of $\mathrm{F}_{1}^{220}$ and $\mathrm{Fr}^{221}$ lie close to the G-N-Curve for Fir, while $\mathrm{Fr}^{219}$ lics much above the curve (Fig. 7). Precise experimental values are required for these.

\section{(88) Radium}

The known isotopes of $\mathrm{Ra}$ range from $\mathrm{Ra}^{2 \% 2}$ to $\mathrm{Ra}^{22 y}$ (MsThI) with the exception of $\mathrm{Ra}^{227}$. The useful data are given in Table VI.

$\mathrm{Ra}^{222}$ : This is $\beta$-stable as expected from $\beta$-energetics, and is only $\alpha$-active. The $\alpha$-energy has not been obtained from separaterl isotope but is assigned in order of half-life.

$\operatorname{Ra}^{223}$ (AcX): As reviewed by Bethe (1937), the a-spectra of AcX is complex consisting of four groups. The intensity of group zero d-particles is $4 \%$. The observed disintegration coustant is uscd to give $\lambda_{\alpha_{0}}$ equul to $2.86 \times 10^{-7}$ sec. $^{-1}$.

The $\beta$-stability of $\mathrm{Ra}^{223}$ is explained by $\beta$-energetics considerations.

$\operatorname{Ra}^{224}(\mathrm{ThX}):$ The $\alpha$-particles of $\mathrm{Th}^{224}$ are homogeneous according to the investigation of Briggs (1936).

$\mathrm{Ra}^{225}:$ This isotope is a member of the $(4 n+1)$ radio-active series. The $\beta^{-}$-activity of $\mathrm{Ra}^{22 !}$ is in agreement with the studies of $\beta$-energetics. It is $a$ 


\section{Geiger-Nuttall Relationship}

descendant of $7 \times 10^{4}$ yr $\alpha_{\text {-active }} \mathrm{Th}^{229}$. Hence it is plausible that feeble

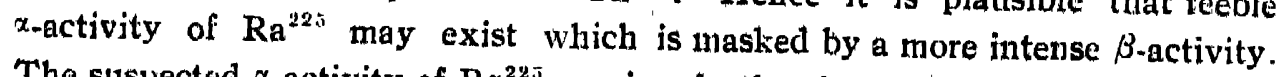

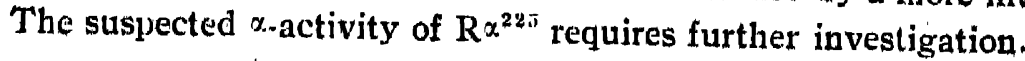

$\mathrm{Ra}^{226}$ : The $\%$-particles from $\mathrm{Ra}^{2 \pm 6}$ are not homogeneous, but belong two groups (Lewis and Bowden, 1934). The intensity of Group O particles is $97.8 \%$ from which $\lambda a_{11}$ is estimated as $I .35 \times 10^{-11} \mathrm{sec}^{-1}$

$\mathrm{Ra}^{227}$ : This $\mathrm{Ra}$ isotope is not yet known. It may be formed if weak a-activity of $\mathrm{Th}^{231}$ is detected which is not unlikely. This will show $\beta^{-}$-activity according to $\beta$-energetics studies.

\section{'TABLE VI}

Radium (88)

\begin{tabular}{|c|c|c|c|c|c|c|c|c|}
\hline Inotopes & $\left|\begin{array}{l}\text { obsserved } \\
\text { half.life } \\
-\end{array}\right|$ & $\stackrel{\alpha}{\beta}$ ratio & $\begin{array}{c}\text { a-half } \\
\text { life } \\
-.\end{array}$ & $\begin{array}{c}\lambda \alpha \\
\left(\operatorname{Sec}^{-1}\right)\end{array}$ & $\begin{array}{c}\text { a.energy } \\
\text { (MeV) }\end{array}$ & $\begin{array}{l}\text { Decay } \\
\text { Energy, } \\
E(\mathrm{MeV},\end{array}$ & Produced by & Remarks \\
\hline $\mathrm{Ra}^{282 \mathrm{z}}$ & $\begin{array}{c}38 s \\
\left(S_{12)}\right.\end{array}$ & ." & $3^{4} s$ & $\cdots$ & $\begin{array}{c}6.5 \\
\left(S_{12}\right)\end{array}$ & 6.61 & $T^{\prime 2} h^{226} a$-decay & $\cdots$ \\
\hline 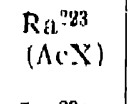 & $\begin{array}{l}11.2 \mathrm{dl} \\
(16)\end{array}$ & $\cdots$ & $11.2 \mathrm{~d}$ & $7.14 \times 10^{-7}$ & $\begin{array}{l}5.72 \\
\left(\mathrm{~L}_{4}\right)\end{array}$ & 5.82 & RdAc $c^{227} \alpha$-decay & $\begin{array}{c}\text { Datn require } \\
\text { redeler- } \\
\text { mination }\end{array}$ \\
\hline $\begin{array}{l}\mathrm{Ka}^{224} \\
\left(\mathrm{I}^{\prime}(1) \mathrm{X}\right)\end{array}$ & $\begin{array}{l}3.61 \mathrm{~d} \\
\left(\mathrm{I}_{3}\right)\end{array}$ & $\cdots$ & $3.64 \mathrm{~d}$ & $2.2 \times 10^{-6}$ & $\begin{array}{l}5.68 \\
\left(13_{3}\right)\end{array}$ & 5.78 & $\mathrm{Rd}^{\prime} \mathrm{Th}^{22 R_{\alpha-\mathrm{d}} \mathrm{dec} a y}$ & $\ldots$ \\
\hline$R^{2} i^{225}$ & 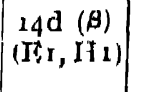 & $\ldots$ & $\cdots$ & $\cdots$ & ... & $\cdots$ & $\mathrm{Th}^{229} \alpha$-decay & $\begin{array}{l}\text { a activity. } \\
\text { probable }\end{array}$ \\
\hline $\mathrm{Rit}^{226}$ & $\begin{array}{c}1590 y \\
(1(1))\end{array}$ & $\cdots$ & r $590 \mathrm{y}$ & $\begin{array}{c}1.38 \times 10^{-11} \\
\lambda_{110}=1.35 \\
\times 1011\end{array}$ & $\begin{array}{l}4.79 \\
(\mathrm{~L} / 1)\end{array}$ & 4.88 & $\mathrm{I}_{0} 230 \alpha$-decay & $\ldots$ \\
\hline $\mathrm{Ra}^{227}$ & : & $\ldots$ & $\cdots$ & $\cdots$ & $\cdots$ & $\cdots$ & $\cdots$ & $\begin{array}{l}\beta^{-} \text {-activity } \\
\text { expected }\end{array}$ \\
\hline $\begin{array}{c}\mathrm{Ra}^{\mathrm{y} 2 \mathrm{~g}} \\
(\mathrm{NISTh})\end{array}$ & $\begin{array}{c}6.7 \mathbf{v}(\dot{\beta}) \\
(\dot{c} 6)\end{array}$ & $\cdots$ & $\cdots$ & .. & $\cdots$ & $\cdots$ & $T^{T} h^{272} \alpha$-decay & $\begin{array}{l}\text { neak a-acti- } \\
\text { vity probable. }\end{array}$ \\
\hline
\end{tabular}

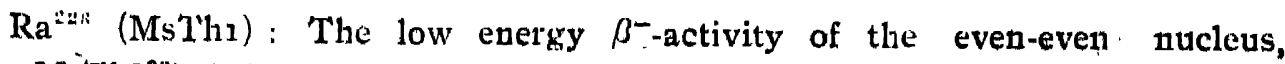
${ }_{n} \mathrm{Ms}^{\prime} \mathrm{Th}^{2{ }^{2: h}}$ is in good agreement with Saha-Saha theory as indicated in the $\beta$-energetics study of the Group $I=52$. Since it is the decendant of $x \cdot 39 \times 1$ ${ }^{10^{10}} \mathrm{yr}^{\mathrm{x}}$-active $\mathrm{Th}^{232}$, it is likely that $\alpha$-activity also occurs for MsThI with a half-life of the order of a million years which is probably overshadowed by the more intense $\beta^{-}$-activity. The probable $\alpha$-activity of $\mathrm{MsThl}$ is to be searched for.

\section{The refined Geiger-Nuttall Curve for Ra.}

The plot of the experimental data in Table VI is given in Fig. 7. It is observed that out of four $\alpha$-active isotopes of $\mathrm{Ra}$, one point $\mathrm{Ra}^{22 \mathrm{~s}}$. do not fall on the smooth curve. Same anomaly in the experimental data is seen to exist in case of $\Lambda c X^{223}$ and $\mathrm{ThX}^{224}$. The $\alpha$-evergy values of these are 5.7 .49 
and $5.68 \mathrm{I} \mathrm{MeV}$ respectively according to spectroscopic determination of Lewis and Bowden (1934) and Briggs (1936); But the disintegration constant $\lambda_{a}$ of $\operatorname{ThX} X^{\prime 24}$ having lower $\alpha$-energy is given as grealer than $\lambda_{a}$ for $\mathrm{AeX}^{223}$. These data are incompatible with the theory of $\alpha$-activity. The data for $\mathrm{Ra}^{\mathrm{i}: 3 \mathrm{a}}$ (ACX) should be re-investigated and revised.

\section{(89) Actinium}

The isotopes of $A c$ range from $A c^{22: 3}$ to $A c^{228}$ with the exception of $A c^{226}$. The relevant data are given in 'Table VII.

$\mathrm{Ac}^{22.3} \eta$ his should exhibit $K$-capture in addition to observed $\alpha$-activity.

\section{TABIE VII}

Actinium $(89)$

\begin{tabular}{|c|c|c|c|c|c|c|c|c|}
\hline Isotopes & $\begin{array}{l}\text { Obscryed } \\
\text { hall-life }\end{array}$ & $\begin{array}{|ll|}\boldsymbol{\beta} & \text { ratio } \\
\end{array}$ & $\begin{array}{c}\alpha-\text { Lhalt- } \\
\text { life }\end{array}$ & $\begin{array}{l}\lambda a \\
\left(\sec ^{-1}\right)\end{array}$ & $\begin{array}{c}\alpha-\text { energs } \\
\text { (MeV) }\end{array}$ & $\begin{array}{l}\text { Dccay } \\
\text { energy } \\
J E\left(M_{C} V^{\prime}\right)\end{array}$ & Produced hy & Remarks \\
\hline $\mathrm{Ac}^{223}$ & $\widetilde{T}_{(\mathbf{a} 2 a)}^{2 m i}$ & $\cdots$ & $\sim 2 \mathrm{ml}$ & $1.16 \times 10^{-2}$ & $\begin{array}{l}6.64 \\
((62 a)\end{array}$ & 676 & $\mathrm{~Pa}^{227} \alpha$-decay & $\begin{array}{l}K \cdot \text { capture acti- } \\
\text { vity probahle. }\end{array}$ \\
\hline$\Lambda c^{2 \lambda_{1}}$ & $\tilde{(G 2 a)}_{2.5 \mathrm{l}}$ & $\begin{array}{l}n \\
k\end{array}$ & $27.5 \mathrm{~b}$ & $7.7 \times 11^{-6}$ & $\begin{array}{c}(\hat{6.17}) \\
\left(\mathrm{G}_{22}(x)\right.\end{array}$ & 6.28 & $I^{\prime} a^{22 R} \alpha-$ decay $y$ & $\begin{array}{l}\text { I'recise datal } \\
\text { required }\end{array}$ \\
\hline $\mathrm{Ac}^{225}$ & $\operatorname{lod}_{\left(\mathrm{E}_{\mathrm{I}}, \mathrm{H}_{\mathrm{I}}\right.}^{\mathrm{od}}$ & $\cdots$ & 1od & $8.02 \times 10^{7}$ & $\begin{array}{l}5 . \mathrm{FoI}^{\circ} \\
(\mathrm{E} 1 \mathrm{I})\end{array}$ & 5.906 & $\operatorname{Ra}^{295 \beta^{-} \text {-decay }}$ & $\cdots$ \\
\hline $\mathrm{Ac}^{286}$ & $\ldots$ & $\begin{array}{l}\cdots \\
I\end{array}$ & ... & $\vdots$ & $\ldots$ & $\ldots$ & $\ldots$ & $\begin{array}{l}\text { 'this will be } \\
\beta^{-} \text {-active. }\end{array}$ \\
\hline$\Delta c^{227}$ & $\begin{array}{l}33.5 y \\
(C 6)\end{array}$ & $\left(\mathrm{P}_{1}, \mathrm{P}_{2}\right)$ & $\tau_{35}$ & i. $63 \times 11^{-11}$ & $\left(\mathrm{P}_{1}^{5}, \mathrm{P}_{2}\right)$ & 5.09 & $\mathrm{~Pa}^{2311} a$-decay & \\
\hline $\begin{array}{c}\Delta c^{229} \\
\text { (MisThII) }\end{array}$ & $\begin{array}{l}\text { 6.j. } 3 \mathrm{~h} \\
\text { (Ch) }\end{array}$ & $\begin{array}{cc}\frac{a}{\beta} & ? \\
\left(G_{5}, G_{5}\right)\end{array} \mid$ & $\cdots$ & $\cdots$ & $\left(\mathrm{r}_{5}^{4.5}, \mathrm{G} 66\right)$ & $4.5^{8}$ & $\mathrm{M}: \mathrm{Th}^{228} \boldsymbol{\beta}$-decay & \\
\hline
\end{tabular}

$\mathrm{Ac}^{224}$ : The observed $K$-capture activity along $u$ ith $\alpha$-etuission is in agreement with $\beta$-energetics considerations.

$A c^{225}:$ This is a member of the recently discovered $(4 \mathrm{n}+x)$ radioactive series. The $\beta$-stability of this isotope is in agreement with the $\beta$-energetics studies.

$A c^{226}$ : This isotopes is not yet known. If ever obtained, it will be predominantly $\beta^{-}$-active.

$\mathrm{Ac}^{227}$ : Perey and Lecoin (r939) discovered that along with strong $\beta^{-}$-activity of $\mathrm{Ac}^{227}$, a weak $\alpha$-activity exists to the extent of $1: 99$. The $\beta$-activity of $\mathrm{Ac}^{227}$ is in agreement with $\beta^{-}$-energetics studies. The $\alpha$-branching of $\mathrm{Ac}^{227}$ produces $\mathrm{AcK}$, which is an isotope of element 87 .

$\mathrm{Ac}^{228}$ (MsThII): This predominatly $\beta^{-}$-active isotope bas been reported to be very weakly $\alpha$-active by Gueben (1933). The branching ratio, as well 


\section{Geiger-Nuttall Relationship}

as the $\alpha$-decay product, $\mathrm{Fr}^{22 n}$ has not yet been observed. The $\alpha$-energy is reported as $4.5 \mathrm{MeV}$ from range measurement. This nucleus requires further studies.

Taking the $\alpha$-energy to' be correct, the modified Geiger-Nuttall Cul ve can be used to find out $\lambda_{a}$ for $\mathrm{Ac}^{22 R}$. The $\alpha$-half-life comes out as $1.5 \times 10^{n}$ years, from which $\alpha: \beta$ branching ratio becomes $5 \times 10^{-8}: x$.

\section{Modified Geigcr-Nuttall Curve for Ac:}

Of four isotopes of Ac, three points lie on the smooth $\mathrm{G}-\mathrm{N}$ Curve for Ac (Fig. 7) only $A^{224}$ talls outside. Precise determinations of $\lambda, F_{\alpha}$ and $\kappa: \alpha$ ratio are required for $A^{224}$. The unknown data for $\mathrm{Ms}^{2} \mathrm{ThII}^{2 g_{R}}$ can be roughly estimated from this curve. Taking the $\alpha$-encrgy data of MsThII to be correct, the $\alpha$-half-life and the ratio of $\alpha: \beta$ emissions are calculated as given above.

\section{(oo) Thorium}

The isotopes of ${ }^{\top} \mathrm{Th}$ range from $\mathrm{Tl}^{220}$ to $\mathrm{Th}^{234}$. Five of them are $\alpha$-active. 'The relevant data are tabulated in Table VIII.

$\mathrm{Th}^{226}:$ No other activity is expected from $\beta$-energetics studies. $\mathrm{T}^{2{ }^{227}}$ (Rd Ac) : As observed by Lew's and Bowden (1934) the $\alpha$-spectra of RdAc is found to he highly complex consisting of eleven $\alpha$-groups. The spectra is of Class I and the intensity of (iroup, $O \alpha$-particles is $24 \%$. From this the value of $\lambda_{a 0}$ comes out as $\mathrm{I} .0 \mathrm{I} 8 \times \mathrm{IO}^{-7} \mathrm{sec}^{-1}$.

$\mathrm{Th}^{2 \mathrm{2N}}\left(\mathrm{Rd}^{\prime} \mathrm{Th}\right.$ ): 'The studies of Lewis and Bowden (1934) revealed the $\alpha$-spectra from $\mathrm{Rd}^{\prime} \mathrm{Th}^{228}$ to be complex consisting of two groups. The intensily of Group $O \alpha$-particles is $85 \%$. The partial disintegration constant $\lambda_{\text {a o }}$ comes out as $9.33 \times 10^{-9} \mathrm{sec}^{-1}$. Energetically no other activity is probable for this.

Th' $\mathrm{h}^{221}$ : This one is a member of the $(4 \mathrm{u}+\mathrm{I})$ radioactive series. The experimental data are rather preliminary. Very weak $\beta^{-}$-activity is not unlikely from $\beta$-energetics consideration.

' $\mathrm{I}^{2 \mathrm{gsin}}$ (Io): The $\alpha$-particles are homogeneous. The $\alpha$-energy valuc given by Winand (r937) appear satisfactory from the Geiger-Nuttall Curve for $\mathrm{Th}$.

$\mathrm{Th}^{281}$ (UY) : The obscrved $\beta^{-}$-activity of $\mathrm{Th}^{2: 1}$ is in agreement with energetics consideration. As it is the $\alpha$-decay product of $U^{23.5}$ this isotope is strongly suspected to show $\alpha$-activity with long life like $\mathrm{Ac}^{227}$. This possibly remains masked by strong $\beta^{-}$-activity. This $x$ equires further studies.

$\mathrm{Th}^{23:}$ : The energy of $\alpha$-particles from uatural thorium is different investigators. Ionisation chamber measurements by Schiritjmeister (1937) give $\alpha$-energy as $4.2 \mathrm{MeV}$. Latest determination is due to Faraggi (1936) who 
TABLE VIII

Thorium (9o)

\begin{tabular}{|c|c|c|c|c|c|c|c|c|}
\hline Is itupe & $\begin{array}{l}\text { Observed } \\
\text { half.life }\end{array}$ & $\frac{\alpha}{\beta}$ ratio & a-half-life & $\begin{array}{c}\lambda_{a} \\
\left(\mathrm{Sec}^{-1}\right)\end{array}$ & $\left|\begin{array}{c}a-\text {-cner } h y \\
\left(\mathrm{MeV}^{\prime}\right)\end{array}\right|$ & $\begin{array}{c}\text { Decay } \\
\text { energy } \\
E(\mathrm{MeV})\end{array}$ & Produced by & Remarks \\
\hline $\mathrm{Th}^{226}$ & $\begin{array}{l}30.9 \mathrm{~m} \\
(\mathrm{~S} 121\end{array}$ & & $.30 .9 \mathrm{~m}$ & $3.74 \times 10^{-4}$ & $\begin{array}{l}6.3 \\
\text { (Siz) }\end{array}$ & $64 \mathrm{I}$ & $\mathrm{U}^{230} \alpha$-decay & $\cdots$ \\
\hline $\begin{array}{l}\mathrm{Th}^{227} \\
(\mathrm{Rd} d \mathrm{c})\end{array}$ & $\begin{array}{l}\text { r8..9d } \\
(c 6)\end{array}$ & $\cdots$ & $18.9 \mathrm{~d}$ & $\begin{array}{c}4.24 \times 10^{-7} \\
\lambda_{a n}=1.02 \times 10^{-7}\end{array}$ & $\begin{array}{c}6.049 \\
(\mathrm{~L}, 4)\end{array}$ & 6.556 & $\mathrm{Ac}^{227 \bar{\beta}-\mathrm{dec} a \mathrm{y}}$ & .. \\
\hline 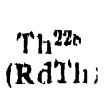 & $\begin{array}{c}\mathrm{x} .90, y \\
(\mathrm{c} 6)\end{array}$ & $\cdots$ & 1 goy (c6) & $\begin{array}{c}1.10 \times 10^{8} \\
\lambda_{n 1}=9.33 \times 109\end{array}$ & $\begin{array}{l}5.418 \\
(\mathrm{I} \cdot \mathrm{A})\end{array}$ & 5.514 & $\underset{\beta \text {-decay }}{\operatorname{MsThII}}$ & ... \\
\hline $\mathrm{Th}^{229}$ & $\underset{(E, x, 111)}{\sim}$ & $\cdots$ & $-5 \times 10^{3} y$ & $1.4 \times 10^{-12}$ & (E) & -5.09 & $\mathrm{U}^{233} \alpha$-decay & $\begin{array}{c}\text { approxi- } \\
\text { mate. }\end{array}$ \\
\hline $\begin{array}{l}T_{1} 1^{230} \\
(10)\end{array}$ & $\begin{array}{c}8.3 \times 10^{4 y} \\
(\sqrt{ } 6)\end{array}$ & $\ldots$ & $8.3 \times 10^{4} y$ & $2.65 \times 10^{-13}$ & $\begin{array}{l}4.81 \\
\text { (W } 3)\end{array}$ & 1.865 & UIII ${ }^{234 a} \cdot$ decay & $\ldots$ \\
\hline $\begin{array}{l}\mathrm{Tl}^{231} \\
(\mathrm{UV})\end{array}$ & $\underset{(\mathrm{c} 6)}{24.6 \mathrm{~h}(\overline{\bar{\beta}})}$ & $\ldots$ & $\cdots$ & $\cdots$ & & $\cdots$ & $\begin{array}{c}\mathrm{Th}^{232(\mathrm{n} 2,211)} \\
\left(\mathrm{N}_{3}\right)\end{array}$ & $\begin{array}{l}\text { activity } \\
\text { probalsle. }\end{array}$ \\
\hline $\mathrm{Th}^{232}$ & $\begin{array}{c}1.39 \times 10^{10} y \\
\left(K_{3}\right)\end{array}$ & $\ldots$ & $1.39 \times 10^{10} \mathrm{y}$ & $1.58 \times 10^{18}$ & $\begin{array}{r}4.2(\mathrm{~S}(6) \\
3.90\left(\mathrm{~F}_{1}\right)\end{array}$ & $\begin{array}{l}4.27 \\
3.97\end{array}$ & $\begin{array}{l}\text { Natural } \\
\text { Source }\end{array}$ & $\cdots$ \\
\hline $\mathrm{Th}^{233: 3}$ & $.23 \mathrm{~m}(\overline{\mathrm{\beta}})$ & $\cdots$ & $\ldots$ & $\cdots$ & $\ldots$ & $\ldots$ & $\begin{array}{l}\mathrm{Th}^{232}(\mathfrak{n}, \gamma) \\
(\mathrm{Mz})\end{array}$ & $\cdots$ \\
\hline $\begin{array}{l}\mathrm{Th}^{2394} \\
\left(\mathrm{TX}_{1}\right)\end{array}$ & $\begin{array}{c}24 . \sin (\beta) \\
(\mathrm{c} 5,84)\end{array}$ & $\cdots$ & $\ldots$ & $\cdots$ & $\cdots$ & $\ldots$ & I $^{23 q^{a}} a$-1ecay & $\begin{array}{l}\text { aediva } \\
\text { activity } \\
\text { probabje. }\end{array}$ \\
\hline
\end{tabular}

determined the range of $\alpha$-particles by photographic method. With the rangecuergy curve by Holloway and Livingstone (1938), $L_{a}$ becomes $3.90 \mathrm{MeV}$. This value appears too low.

$\mathrm{Th}^{2: 4}$ : This, being the decay product of long-lived $\mathrm{U}^{2.3 \mathrm{k}}$, is expected to show weak $\alpha$-activity which probably remaius masked by strong $\beta^{-}$-activity.

\section{Geiger-Nuttall Curve for Th.}

With the clata given in Table VIII a continuous curve can be drawn through the five plotted points (Fig. 8) and only $\mathrm{Th}^{227}$ falls outside. In case of $\mathrm{Th}^{232}$ isotope the $\alpha$-energy is not consistent for different works. The modific Geiger-Nuttall curve gives us the clue regarding the cornectness of the values of $E_{a}$. As obscrved from this curve, in case of $1 h^{2.22}$, the value of Schintlmeister (1937) appear more salisfactory than the other.

\section{(91) Protoartinium}

(Of six known isotopes of $\mathrm{Pa}$, three are $\alpha$-active. The data are given in Table IX.

$\mathrm{Pa}^{227}$ : This is the starting member of the co-lateral chain of Ac series. 'The $K$-capture activity is in agreement with $\beta$-encrgetic studies. 
$\mathrm{Pa}^{238}$ : This is the starting member of the colateral thain of $\mathrm{Th}$ series. This show s high- $K$-capture activity as expected from $\beta$-energetics.

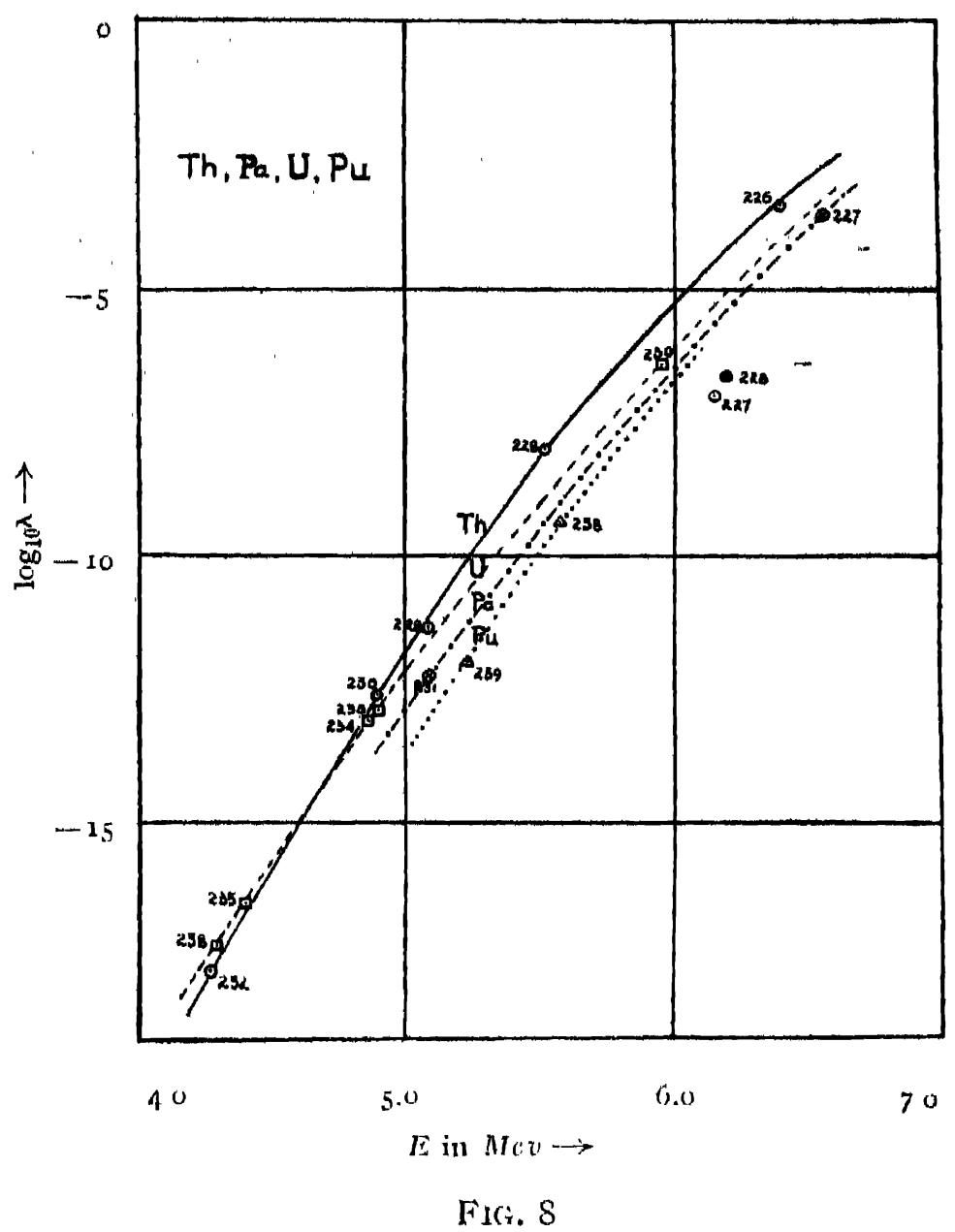

$\mathrm{Pa}^{{ }^{2 i y}}$ : Not yet known. According to $\beta$-energetics, this will decay by $K_{\text {icapture. }}$

$\mathrm{Pa}^{2 * a}$ : The $\beta$-activity of this follows from $\beta$-energetics stucies.

$\mathrm{Pa}^{231}$ : The $\alpha$-particles from this isotope, so long known to be homogeneous have recently been shown to have fine structure by San-Tsiang et al (1946). Three groups of $\alpha$-particles of energies 5.00, 4.72 and $4.69 \mathrm{McV}$ are found; the intensity of group $\circ \alpha$-particles is about $8 \mathrm{r} \%$. Thus $\lambda_{\alpha 0}$ becomes $5.59 \times 10^{-13} \mathrm{sec}^{-1}$.

$\mathrm{Pa}^{232}$ : Not yet known. May be obtained from $\mathrm{Pa}^{2 s 1}(\mathrm{n}, \gamma)$, reaction. This isotope will show precominant $\beta^{-}$-activity. studies.

$\mathrm{Pa}^{233}$ : The observed $\beta^{--a c t i v i t y ~ i s ~ i n ~ g o o d ~ a g r e e m e n t ~ w i t h ~} \beta$-energetics 
$\mathrm{Pa}^{234}\left(t \mathrm{X}_{2}, \mathrm{UZ}\right)$ : Two isomeric nuclei exists for $\mathrm{Pa}^{234},{ }_{94} \mathrm{UX}_{1}{ }^{234}$ goes

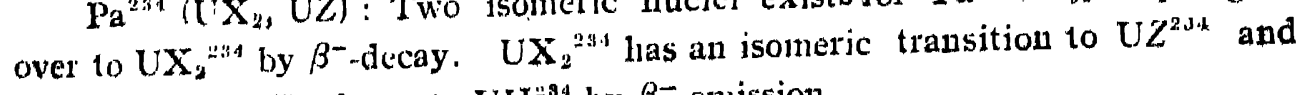
both $U X_{2}$ and $U Z$, decay to UII"34 by $\beta^{-}$-enission.

\section{TABLE IX}

Protoactinium (91)

\begin{tabular}{|c|c|c|c|c|c|c|c|c|}
\hline I sotopes & $\begin{array}{c}\text { (Ohserved } \\
\text { hallf-life }\end{array}$ & $\frac{\alpha}{\beta}$ ratos & $a$-hall-life & $\left(\sec ^{\lambda_{u}}\right)$ & $\begin{array}{c}\text { B-energy } \\
(\mathrm{MeV})\end{array}$ & $\begin{array}{l}\text { Decny } \\
\text { cinerg: } \\
\text { E(MeV) }\end{array}$ & Produced by & Remarks \\
\hline$P^{2} a^{2: 27}$ & $38 \mathrm{~m}$ & $\frac{a}{\alpha}--\frac{5}{1}$ & 45. $6 \mathrm{~km}$ & $2.5 .3 \times 10^{4}$ & $\begin{array}{l}0.46 \\
\left(G_{2} a\right)\end{array}$ & 6.57 & $\mathrm{Th}^{232}(\mathrm{~d} 7 \mathrm{n})$ & \\
\hline $\mathrm{I}^{\prime 2} \mathrm{a}^{294}$ & $\begin{array}{c}22 \mathrm{~h} \\
(\mathrm{G} ; a)\end{array}$ & $\frac{a}{\mathrm{~K}} \sim \frac{\mathrm{I}}{50}$ & 46801 & $168 \times 10^{-7}$ & $\begin{array}{l}6.09 \\
\left(G_{2} \alpha\right)\end{array}$ & 6.20 & $T^{2} h^{232}(\mathrm{~d}, 6 \pi)$ & \\
\hline $\mathrm{Pg}^{2 z \alpha 9}$ & " & & $\cdots$ & $\cdots$ & $\ldots$ & $\cdots$ & $\mathrm{Th}^{238}(\mathrm{~d}, 4 \mathrm{n})$ & $\begin{array}{l}\text { This will } \\
\text { show } K- \\
\text { cept ure }\end{array}$ \\
\hline $\mathrm{Pa}^{230}$ & $\begin{array}{c}17 \mathrm{~d}(\tilde{\beta}) \\
\left(\mathrm{S}_{2}\right)\end{array}$ & . & $\cdots$ & $\cdots$ & $\ldots$ & $\ldots$ & $\mathrm{Th}^{233}(\alpha, \mathrm{p} 5 \mathrm{D})$ & \\
\hline $\mathrm{Pa}^{\mathrm{za1}}$ & $\begin{array}{c}3.2 \times 10^{4} y \\
\left(\left(_{3}\right)^{3}\right.\end{array}$ & .. & $3.2 \times 10^{4} y$ & $\mid \begin{array}{c}6.9 \times 10^{-13} \\
\lambda_{140}=56 \times 10^{-13}\end{array}$ & $\mid \begin{array}{l}50 \\
\left(\mathrm{~S}_{3}\right)\end{array}$ & 5.119 & UY ${ }^{231} \beta^{-}$-deray & This will \\
\hline$I^{\prime} a^{2 / 22}$ & $\because$ & $\ldots$ & $\cdots$ & ... & $\cdots$ & $\cdots$ & $\cdots$ & $\begin{array}{l}\text { decay by } \\
\bar{B} \text {-activity. }\end{array}$ \\
\hline $\mathrm{Pa}^{233}$ & $\begin{array}{c}274 \mathrm{~d}(\boldsymbol{\beta}) \\
\left(3_{4}\right)\end{array}$ & .. & .. & $\ldots$ & $\cdots$ & $\cdots$ & $\mathrm{Th}^{239} \beta$ \decay & \\
\hline$I^{\prime} u^{234}$ & $f .71,(\ddot{\beta})$ & .. & $\ldots$ & .. & $\ldots$ & $\ldots$ & $\mathrm{UX}_{2} \mathrm{I} \cdot \mathrm{T}$ & \\
\hline $\begin{array}{l}\left(\mathrm{UZ}_{2}\right. \\
\left.\mathrm{UX} \mathrm{X}_{2}\right)\end{array}$ & $\begin{array}{c}1.14 \mathrm{~m}(\dot{\beta}) \\
\mathrm{I} . \mathrm{T}\end{array}$ & $\ldots$ & & $\cdots$ & $\ldots$ & $\cdots$ & $\mathrm{UX}_{1} \beta^{-}$-decay & \\
\hline
\end{tabular}

Ciciger-Nuttall Curve for Pa.

Of three isotopes, $\mathrm{Pa}^{2: 4}$ lies a little below the G-N curve for $\mathrm{Pa}$ (Fig. 8). This is probably due to the approximate value of $\alpha: K$ ratio.

\section{(yz) Uranium}

At present seven isotopes of $U$ are known. Four of these are $\alpha$-active. The relevant data are given in Table $\mathrm{X}$.

$\mathrm{U}^{2 * n}:$ This is $\beta$-stable as expected.

$\mathrm{U}^{232}$ : Not yet known. Expected to show $\alpha$-activity.

$\tilde{T}^{2 s 3}$ : This recently discovercd isotope of $U$ is highly fissionable and this is the starting isotopes in the $(4 \mathrm{n}+\mathrm{I})$ radioactive series.

$U^{234}$ : The experimental data for $\alpha$-energy vary for different investigators by different methods. Latest determiuation oi $\alpha$-encrgy by range measurement in ionisation clamber by Wytzes and Van de Maas (1947) yield a-energy as $4.78 \mathrm{MeV}$. 
TABIE X

Uranium (92)

\begin{tabular}{|c|c|c|c|c|c|c|c|c|}
\hline Isotopes & $\begin{array}{l}\text { Obscrved } \\
\text { half life }\end{array}$ & $\frac{\alpha}{\beta}$ ratio & $a$-half life & 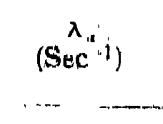 & $\begin{array}{l}\text { a enetgy } \\
\text { (MeV) }\end{array}$ & $\begin{array}{c}\text { Decay } \\
\text { energy } \\
E,(\mathrm{MeV})\end{array}$ & Produced by & Remarks \\
\hline$U^{230}$ & $\begin{array}{l}20.8 \mathrm{~d} \\
(\mathrm{Sr} 2)\end{array}$ & $\cdots$ & $20.8 \mathrm{~d}$ & $3.86 \times 10^{-7}$ & $\begin{array}{l}5.86 \\
.(S 12)\end{array}$ & 5.96 & $\mid \begin{array}{c}x^{3} a^{230} \beta \text {-decay } \\
1^{4} h^{282}(a, 6 u)\end{array}$ & $\cdots$ \\
\hline T] & $\cdots$ & $\cdots$ & $\cdots$ & $\cdots$ & $\cdots$ & $\cdots$ & $\because$ & $\begin{array}{l}\alpha \text {-activity } \\
\text { expected }\end{array}$ \\
\hline $\mathrm{U}^{2333}$ & $\begin{array}{c}1.63 \times 10^{5} y \\
(\mathrm{E}, \mathrm{H}, \mathrm{HI})\end{array}$ & $\cdots$ & $1.63 \times 10^{5} \mathrm{y}$ & $1.35 \times 10^{-13}$ & $\begin{array}{c}4825 \\
(\mathrm{E}, \mathrm{r}, \mathrm{H} t)\end{array}$ & 4.898 & $\mathrm{Ph}^{233} \beta^{-2} \mathrm{~Pa}^{2 \sqrt{3}} \beta$ & \\
\hline $\begin{array}{l}\text { U1234 } \\
\text { (IIII) }\end{array}$ & $\left\{\begin{array}{c}2.69 \times 10^{5} y \\
(\mathrm{NI})\end{array}\right.$ & $\cdots$ & $2.70 \times 10^{5} y$ & $8.14 \times 10^{-14}$ & $\begin{array}{l}4.71\left(\mathrm{IR}_{1}\right) \\
4.78\left(\mathrm{~S}_{10}\right) \\
4.76\left(\mathrm{~S}_{5}\right)\end{array}$ & 4.86 & $\mathrm{~Pa}^{234} \beta^{\mathrm{N}}$-decay & \\
\hline $0^{236}$ & $\begin{array}{c}7.13 \times 10^{8} \mathrm{y} \\
\left(\mathrm{N}_{\mathrm{I}}\right)\end{array}$ & $\cdots$ & $7.13 \times 10^{8} y$ & $3.08 \times 10^{-17}$ & $\begin{array}{l}4.78\left(\mathrm{WA}_{4}\right) \\
4.33\left(\mathrm{VI}_{\mathrm{I}}\right)\end{array}$ & 4.40 & $\begin{array}{l}\text { Natural } \\
\text { Source }\end{array}$ & 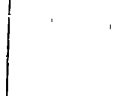 \\
\hline$U^{296}$ & $p$ & $\cdots$ & $\cdots$ & $\cdots$ & $\cdots$ & $\cdots$ & $\mathrm{U}^{235}(\mathrm{u}, \gamma)$ & $\begin{array}{l}\text { Instantly } \\
\text { fissioned }\end{array}$ \\
\hline[]$^{237}$ & $\left.\min _{1}, \mathrm{~N}_{2}\right)$ & $\cdots$ & $\cdots$ & $\cdots$ & $\cdots$ & $\cdots$ & $\begin{array}{r}U^{298}(\mathrm{n}, 2 \mathrm{n}) \\
\left(\mathrm{M} \pi, \mathrm{N}_{2}\right)\end{array}$ & $\cdots$ \\
\hline$U^{239}$ & $45^{6 \times 109} \mathrm{y}$ & $\cdots$ & $4.56 \times 10^{9} y$ & $4.82 \times 10^{-18}$ & $\begin{array}{l}4 . I_{5}\left(\mathrm{R}_{1}\right) \\
4.23\left(\mathrm{~S}_{10}\right) \\
4.2 \mathrm{I}\left(\mathrm{S}_{5}\right)\end{array}$ & 4.29 & $\begin{array}{l}\text { Natural } \\
\text { Source }\end{array}$ & $\cdots$ \\
\hline $\mathrm{U}^{299}$ & 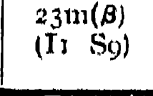 & $\cdots$ & $\cdots$ & $\cdots$ & $\begin{array}{c}4.21\left(W_{4}\right) \\
\ldots\end{array}$ & $\cdots$ & $\begin{array}{c}\mathrm{U}^{238}(\mathrm{n}, \gamma) \\
(\mathrm{HI} I A)\end{array}$ & $\cdots$ \\
\hline
\end{tabular}

$\mathrm{U}^{2,25}$ : The $\alpha$-energy is obtained from the range of $\alpha$-particles and the range-energy relation of Holloway and Livingstone (1938).

$\mathrm{U}^{234}$ : The isotope $\mathrm{U}^{230}$ is not yet known. $\mathrm{U}^{235}$ by netutron capture becomes $U^{236}$ which instantly undergoes fission.

$\mathrm{U}^{23 r}$ : The obscrved $\beta^{-}$-activity of $U^{2: 17}$, is in agreement with the $\beta$-energetics studies.

$\mathrm{U}^{23 \mathrm{~K}}$ : The results of valious investigalions regarding a-energy of $\mathrm{U}^{23 \mathrm{~K}}$ varies to certain exlent. Latest range determination by Wytzes and Van de Maas (1947) yield $\alpha$-energy as 4.2I MeV. T'he $\alpha$-particles are of homogenous etuergy.

$\mathrm{U}^{231}$ : The olsserved $\beta^{-}$-activity of $\mathrm{U}^{239}$ is in accordance with the energetics studies. The $\beta^{-}$energy has not yet heen neasured.

The Geiger-Nuttall Curve for $U$.

With the data given in Table $\mathrm{X}$, the $\log \lambda, E$ curve for the isotopes of $U$ is drawn (Fig. 7). It is seen that all of five $U$ isotopes lie on a smooth G-N curve for $U$.

\section{(93) Neplunium}

$\mathrm{Np}^{237}$ is the only $\alpha$-active isotope of $\mathrm{Np}$ known'so far, The value of $\alpha$-energy is not yet known.

4-1752P-2 


\section{(94) Plutonium}

Three isotope of plutonium are known two of which $\mathrm{Pa}^{34}$ and $\mathrm{Pa}^{3 / 38}$ are $\alpha$ active. The data are given in Table XI.

\section{TABLE XI}

Plutonium (94)

\begin{tabular}{|c|c|c|c|c|c|c|c|c|}
\hline Isnupes & $\begin{array}{l}\text { Chserred } \\
\text { balf life }\end{array}$ & ${ }_{\beta}^{\alpha}$ ralio & $a$ half-lifs & $\begin{array}{l}\lambda_{k} \\
\left(\mathrm{Sec}^{-1}\right)\end{array}$ & $\begin{array}{c}a-4 n+r g s \\
(M e V)\end{array}$ & $\begin{array}{l}\text { Deciay } \\
\text { encrgy } \\
\text { Ei, MeV }\end{array}$ & Troduced by & Remark \\
\hline$J^{3} 1^{236}$ & $\cdots$ & $\cdots$ & $\cdots$ & .. & $\ldots$ & $\ldots$ & 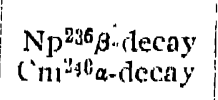 & $\cdots$ \\
\hline $\int^{3}+11^{238}$ & $\begin{array}{l}50 y \\
\text { (S8) }\end{array}$ & $\cdots$ & 5 & $1.39 \times 10^{-10}$ & $5.49\left(\mathrm{C}_{1}\right)$ & $5 \cdot 3^{8}$ & $\begin{array}{l}\mathrm{Np}^{239} \beta-\text { decay } \\
\left(\mathrm{m}^{22^{2} \alpha} \alpha \text {-decay }\right.\end{array}$ & $\cdots$ \\
\hline$\Gamma \mathrm{u}^{239}$ & $\begin{array}{l}24,000 y \\
\text { (S8) }\end{array}$ & $\ldots$ & $\therefore 4,000, y$ & $9.16 \times \mathrm{rr}^{-13}$ & 5.15 & 5.23 & U2:89-decay & $\cdots$ \\
\hline $\mathrm{Pu}^{241}$ & $\operatorname{long}(\hat{\boldsymbol{\beta}})$ &. & ... & $\cdots$ & & $\ldots$ & $\mathrm{U}^{238}(\alpha, 11)(\mathrm{S} 8)$ & $\cdots$ \\
\hline
\end{tabular}

$\mathrm{Pa}^{236}$ : Nothing is reported about this isotope which must have been produced in $\beta-$-decay of $\mathrm{Np}{ }^{3.36}$ and $\alpha$-decay of $\mathrm{Cm}^{3.44}$.

This will be $r$-active, decaying to $\left[l^{2: 2}\right.$.

$\mathrm{Pu}^{23 x}$ : The recent report of the range of $\alpha$-particles from $\mathrm{Pu}^{23{ }^{*}}$ by Chamberlain et al ( $(947)$ yield $\alpha$-encrgy of $5.49 \mathrm{MeV}$ from the range-energy curve (Holloway and Livingstone, I938).

$\mathrm{Pu}^{230}$ : The range measurements by ('hamburlain et al (1947) yield $\alpha$-cDergy as 5 .I $5 \mathrm{MeV}$.

$\mathrm{Pu}^{2 \cdot 1}$ : The observed longlife $\beta^{-}$-activity of $\mathrm{Pu}^{241}$ is in asreement with B-energetices studies.

\section{The Cieiger-Nullall Curve for Pu.}

With two froints corresponding to two $\alpha$-active isolopes of $\mathrm{Pu}$, the long $\lambda, E$ curve is an ajproximate one. The curve is of the same nature as with other elements (Fig.8).

\section{CONCLUSION}

'Thus it is secn that experimental data of all $\alpha$-active nuclei can be plotted quite satisfactorily on seperate Geiger-Nuttall curves for each element. experimental data as some cases are mostly due to the uncertaintics in the ascertaining for any new $\alpha$ out. 'These curves will be of much help in any one of them is known. 


\section{A CKN OW I D D G M N T}

The author expresses his gratitude to Prof. M. N. Saha, F.R.S. for his continued interest and guidance during the progress of the work. The author is also thankful to C.S.I.R. for the award of a scholarship which enabled him to carry out to work.

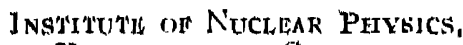

UNIVERSITY OT CATCUT'IA,

R I I F R IENCE

B1. Herlliellot, 1942, J, l'hys, Radium,, 3, 52.

B2. Biswats and Mukler, ee, to)48, Ind. Jour. l'hys, , 22, 80.

133. Briggs, 1936, J'roc. Koy, Soc. Lond A., 157, 183

$\mathrm{B}_{4}$ Brode and Featlicr, 19.17, Proc Roy., Soc. A, 190, 20.

('1. Chamberlain, Gorman, Segre \& Wohl, 1947, l'hys. Rev., 71, 528.

C2. Chang, I946, Phys. Rew., 69, 61.

C2. Condin and Gurncy, 1929, Thys, Rev, 33, 127.

C3. Cork, Halparn and Tate1, 1940, l'hys. Rev, , 87, 37.

C4. Corson, Mackenzie and Scgre, s.9.0, Phys Rcu, 57, 459 \& I087.

C5. Corson, Mackenzic and Segre, x970, Phys. Rev., 68, 672

C6. Curic, Debicrne, Five, Griger, Iahn, I,ind, St. Mever, Rutherford, and Schweidler, 1931, Rew. Mad 1'hys, , 3, 477.

I) I. I)tuw worth, 19.39, Nature, 144, 152.

Ei. Inglish, Cransban, Denuers, Iervey, Hincks, Jelley and May, 1947, Phys Rez., $72,2.53$.

Fx. Liaraggi, rogí, I. Phys. Radium, 7, 353.

G1. Gamow, 1929, Zcits. f. Physik., 52, 5 ro.

62. Cramow, 193\%, Structure of Atomic Nuclei and Nuclear Transformations (Oxfd. Clarendon Press).

G2.. Ghiorso, Meinke and Seaborg, 1948, ,Phys. Rev., 74, 695.

G3. Gratias and Collie, 19.32, Proc. Roy, Soc. Lond. A., 135, 299.

G4. Grosse, Bootl and Dunuing, 19:1, Phys. Rcv, 58, 322.

Gs Gueben 1932, Anr. Sor. Sci Bruxilles, B., B2, 60.

G6. Gueben, I933, Amn Soc, Sci. Broxelles B., 63, II5.

Hr. Hagenanu, Katzin, Studier, Ghiorso and Seaborg, 1947, Phys. Rev., 72,252.

Hr $r_{a}$. Hahn and Strassmant, r939, Naturwiss., 27, II.

H2. Henderson and Lawrence, J137, Phys. Rev., 62, 46 .

$\mathrm{H}_{3}$. Holloway and Livingstone, 19,9. Phys, Rev., 64, 18.

$\mathrm{H}_{4}$ Howland, Templeton and Pcrlnan, 1947, Phys. Rcv.. 71, 552.

$\mathrm{H}_{5}$. Hurst, I,athan and I,ewis, 1940, Proc. Roy. Soc. Lond. A., 174, 126.

Ir. Irvin (jr.) 1939, Phys. Rev., 88, t105.

K) Karlik and Bermerl, 194.3a. Naturatss., 31, 492.

K2. Kariik and I3ernert, 1943b, Naturwiss, 31, 298.

$\mathrm{K}_{3}$. Kavorik and Adams, $1939,1, h y s, R e v, 64,4 \mathrm{r} 3$.

K. Kovarik and Adams, 1941, J. Appl. Phys., 12, 296.

Lr. Latie, t929, Zcit. .. Pliysik, ,62, 726.

L2. Livingstone and Bethe, 1937, Rcv. Mod, Phys, 9, 256 .

I13. Lecoin, 1938, J. Phys. Radium., 9, 8r.

I44. Lewis and Thowden, I934, Proc. Roy. Soc. Lond. A., 156, 235 
Mr. McMillad, r94o, Pliys, Rcv., 68, 178 .

N. Nier, 19,39, J'hys. Rev.. 66, 150.

$\mathrm{N}_{2}$. Nishina, Yasaki, Ezoe, Kimura and Lkawa, xo-10, Phys. Rev., 67, ix82.

N3. Nishina, Tusaki, Kinura and Ikawa, 1938. Nalure . 142, 874.

P's. Perey, 1939, compt. Rend, 208, 97

Pa. Perey and fecoin, s939, I Pliys. Rudiunl., 10, 435 .

P3. L'reston, r945, Phys. Rex', 69, 535 .

P4. Preston, 2917, Phys, Ri, $71,865$.

Rx. Rayton and Wilkins, 1937, linys Kev., 61, 818.

R2. Ringo, 19.40, lliys. Rer., 68, 942

R3. Ringo, 1941, l'llys. Kcv., 69, 107.

R4. Rotbiat, 194x, Jroc. Koy. Soc. Lond. A., 177, 200.

Su. Salla A. K. 1944, l'roc. Nat Tnt. Sci. Ind., 10, 373.

S.. Saha M. N., and Saha A. I , 1946, Trans. Nat. Inst. Sci. Ind., If, J93.

S2. Saha M. N., Sirkar and Mukherece, do40, proc. Nat. Inst. Sri. lud., 6, 45.

S.3. San-'lsiang, luachclet and Bousssiers, 1946, Phys. Rev., 69, 39.

S4. Serrent, 19.39, can I Rescarch A., 17, 103.

is Sichintlueister and Lintncr, 1939, Sit:. Akad, Wiss-1Vicn. Abl. 1la.. 148, $27^{\prime}$

S6. Schintlucister, 1937, Sitz. Akad, Wiss. Wicn. 1bt. 1Ja, 146, 371.

S7. Seaborg, 1044, Rcu Mod. Pliys., 16, s.

S8. Scalucrg, Is46, Scicuce., 104, 379.

So Segre, 1939, J'hys. kive, 55, 15.)4.

S9.. Sexl, 1933, Zits f. Physik, 81, 103.

Sro. Sizon and Wytzes, 1937, 1'hy'sica., 4, 79x.

Si1. Starke, 1942, Natura'iss, 50,577.

S12. Studice and IHyde, 1948, I'lys. Rev', 74, 59J.

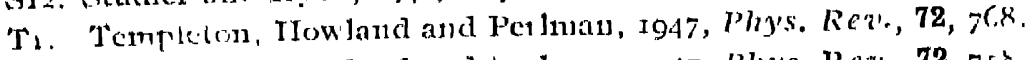

T. Tompletor, Howland and I crluman, 1947, Phys. Rew., 72, 75.

V1. Van J)er Masa and T'ntema, I947, I'hysica., 13, 153.

Wi. Ward, 1942, Proc. Roy. Soc. Lond A, 181, 183.

W2. Wilkius and Crowford, 3938, rhys. Rer., 64, 316.

W3. Winand, Iழ37, J. Phys. Radium., 8, .120.

$W_{4}$. Wylzes and Van der Mass, 1947, Physica,, 13, 49. 